\title{
Phenotypic plasticity triggers rapid morphological convergence
}

3 José M. Gómez ${ }^{1,2 *}$, Adela González-Megías ${ }^{2,3 *}$, Eduardo Narbona ${ }^{*}$, Luis Navarro ${ }^{5 *}$, Francisco

7 1Estación Experimental de Zonas Áridas (EEZA-CSIC), Almería, Spain.

8 2Research Unit Modeling Nature, Universidad de Granada, Granada, Spain.

9 3Dpto. de Zoología, Universidad de Granada, Granada, Spain.

$10{ }^{4}$ Dpto. de Biología Molecular e Ingeniería Bioquímica, Universidad Pablo de Olavide, Sevilla,

11 Spain.

12 5pto. de Biología Vegetal y Ciencias del Suelo, Universidad de Vigo, Vigo, Spain.

13 'Dpto. de Genética, Universidad de Granada, Granada, Spain.

14

15 *Corresponding author. Email: jmgreyes@eeza.csic. (J.M.G.); adelagm@ugr.es (A.G.);

16 enarfer@upo.es (E.N.); lnavarro@uvigo.es (L.N.); fperfect@ugr.es (F.P.); cris@eeza.csic.es

17 (C.A.) 


\section{Abstract}

20 Phenotypic convergence, the independent evolution of similar traits, is ubiquitous in nature,

21 happening at all levels of biological organizations and in most kinds of living beings. Uncovering

22 its mechanisms remains a fundamental goal in biology. Evolutionary theory considers that

23 convergence emerges through independent genetic changes selected over long periods of time.

24 We show in this study that convergence can also arise through phenotypic plasticity. We illustrate

25 this idea by investigating how plasticity drives Moricandia arvensis, a mustard species displaying

26 within-individual polyphenism in flowers, across the morphological space of the entire

27 Brassicaceae family. By compiling the multidimensional floral phenotype, the phylogenetic

28 relationships, and the pollination niche of over 3000 Brassicaceae species, we demonstrated that

29 Moricandia arvensis exhibits a plastic-mediated within-individual floral disparity greater than that

30 found not only between species but also between higher taxonomical levels such as genera and

31 tribes. As a consequence of this divergence, $M$. arvensis moves outside the morphospace region

32 occupied by its ancestors and close relatives, crosses into a new region where it encounters a

33 different pollination niche and converges phenotypically with distant Brassicaceae lineages. Our

34 study suggests that, by inducing phenotypes that explore simultaneously different regions of the

35 morphological space, plasticity triggers rapid phenotypic convergence. 
Introduction

Phenotypic convergence, the independent evolution of similar traits in different evolutionary lineages, is ubiquitous in nature, happening at all levels of biological organizations and in most kinds of living beings (1-3). Convergent evolution plays a fundamental role in how evolutionary lineages occupy the morphological space $(2,4)$. The expansion of lineages across the morphological space is a complex process resulting from the ecological opportunities emerging when species enter into different regions of the ecospace and face new ecological niches $(5,6)$.

46 When this occurs, divergent selection on some phenotypes makes lineages to diversify

47 phenotypically, boosting morphological disparity, triggering a morphological radiation and

48 eventually filling the morphospace $(7,8)$. Because the ecological space saturate as lineages

49 diversify (9), unoccupied regions become rare in highly diversified lineages (10). Under these

50 circumstances, entering into a new region usually entails sharing it with other species exploiting

51 the same ecological niche $(2,10,11)$. In this situation, independent lineages tend to evolve

52 similar phenotypes through convergent evolution (2, 4). In diversified lineages occupying a

53 saturated morphospace, divergent and convergent evolution are ineludibly connected $(10,12)$,

54 and both processes contribute significantly to shape the geometry of the morphospace occupation $(4,11)$.

Uncovering the mechanisms triggering convergence remains a fundamental goal in biology.

58 Evolutionary theory shows that convergent phenotypes emerge from several genetic mechanisms, such as independent mutations or gene reuse in different populations or species, polymorphic alleles, parallel gene duplication, introgression or whole-genome duplications, that are selected over long periods of time (13-15). Under these circumstances, the origin of morphological convergence is mostly slow, occurring over evolutionary time and associated with multiple events of speciation and cladogenesis (11). It is increasingly acknowledged, however,

64 that phenotypic plasticity might elicit the emergence of novel phenotypes with new adaptive possibilities, which may be beneficial in some contexts $(16,17)$. Under these circumstances, plasticity may behave as a facilitator for evolutionary novelty and diversity, shaping the patterns of morphospace occupation $(16,18-21)$. In this study, we provide compelling evidence showing that phenotypic plasticity also plays a prominent role in the emergence of convergent phenotypes. By inducing the production of several phenotypes, plasticity may cause the species to explore different regions of the morphospace almost simultaneously $(18,19)$. This opens the opportunity

71 for plastic species to diverge from their lineages and converge with the species already located in

72 other morphospace regions. We illustrate this idea by investigating how plasticity drives

73 Moricandia arvensis, a species exhibiting extreme polyphenism in flowers (18), across the 
74 morphological space of the entire Brassicaceae family. Moricandia arvensis displays within-

75 individual floral plasticity, with flower morphs varying seasonally on the same individual (18). By

76 studying the multidimensional floral phenotypes, the phylogenetic relationships, and the

77 pollination niches of over 3000 Brassicaceae species, we demonstrate that phenotypic plasticity

78 makes the flowers of this mustard species to diverge from its ancestors and close relatives, to

79 cross into a new region of the ecospace, and to converge morphologically with distant

80 Brassicaceae lineages. This finding has great implications, suggesting that plasticity might not

81 only promote the evolution of novelties and morphological divergence $(16,17,20,21)$ but can

82 also provide an alternative explanation to the pervasiveness of convergence in nature.

Results

\section{Plasticity-mediated floral disparity and divergence}

88 Changes in temperature, radiation and water availability induce the production of different types

89 of flowers by the same M. arvensis individuals; large, cross-shaped lilac flowers in spring but

90 small, rounded, white flowers in summer (18). To quantify the magnitude of floral disparity

91 between these two phenotypes of $M$. arvensis, we first assessed floral disparity for the entire

92 mustard family. Brassicaceae is one of the largest angiosperm families, with almost 4000 species

93 grouped in 351 genera and 51 tribes $(7,22-24)$. We determined the magnitude and extent of

94 floral disparity among 3140 plant species (approx. 80\% of the accepted species) belonging to 330

95 genera (94\% of the genera) from the 51 tribes. Because we were interested in floral characters

96 mediating the interaction with pollinators, we recorded for each studied species a total of 31 traits

97 associated with pollination in Brassicaceae (Supplementary Data 1, Methods). We used the

98 resulting phenotypic matrix to generate a family-wide floral morphospace. We first run a principal

99 coordinate analysis (PCoA) to obtain a low-dimensional Euclidean representation of the

100 multidimensional phenotypic similarity existing among the Brassicaceae species (25). Because

101 the raw matrix was composed of quantitative, semi-quantitative and discrete variables, PCoA was

102 based on Gower dissimilarities (25). We optimized this initial Euclidean configuration by running a

103 non-metric multidimensional scaling (NMDS) algorithm with 5000 random starts (25). The

104 resulting morphospace (Figure 1a) was significantly correlated with the initial PCoA configuration

$105(r=0.40, P<0.0001$, Mantel test $)$ and was a good representation of the original relationship

106 among the species $\left(R^{2}>0.95\right.$, Stress $=0.2$, Figure $\left.1 \mathrm{~b}\right)$. The distribution of the species across the

107 morphospace was significantly associated with different pollination traits (Figure S1; Table S1).

108 Species in the central region were mostly medium-sized plants bearing a moderate to high

109 number of small, polysymmetric white flowers with short corolla tubes, exposed nectaries and 
110 visible sepals (Figure 1a, Figure S1). Species in the bottom right corner were small or prostrate,

111 bearing minute flowers, many time apetalous and with just 2 or 4 stamens, whereas species

112 located in the bottom left corner were medium-sized plants with asymmetric flowers arranged in

113 corymbous inflorescences. Plants with yellow flowers were located in the right region of the

114 morphospace. In contrast, large plants with strongly tetradynamous androceum and large,

115 veined, dissymmetrical to asymmetrical, pink to blue flowers with concealed nectaries, long

116 corolla tubes and bullseyes were located in the upper left region (Figure 1a, Figure S1).

117 Moricandia arvensis, when blooming in spring (Figure 1c), occupies this later peripheral region of

118 the morphospace, close to other Moricandia species (purple dots in Figure 1a). However, during

119 summertime, the individuals of $M$. arvensis are shorter and produce fewer, much smaller flowers

120 with white, unveined and rounded corollas with overlapped petals and green sepals that are

121 mostly arranged alone the floral stems (Figure 1d) (18). Due to this radical phenotypic change,

122 the summer phenotype of $M$. arvensis was located in a different, more central position of the floral

123 morphospace (Figure 1a), far away from the region occupied by the Moricandia species. As a

124 consequence of this jump, the morphological disparity between the spring and summer

125 phenotypes of $M$. arvensis, calculated as their distance in the morphospace (26), was very high

126 (0.264). In fact, it was much higher than the average pairwise disparities among all studied

127 Brassicaceae species (0.155 \pm 0.090 , mean \pm s.e.m., 4,912,545 pairwise disparities) and almost

$12850 \%$ of the largest observed disparity (0.55) (Table S4). This outcome suggests that phenotypic

129 plasticity prompts $M$. arvensis to explore two distant regions of the Brassicaceae floral

130 morphospace simultaneously.

132 To know how intense is the plasticity-mediated M. arvensis disparity, we compared its value with

133 the disparity values observed at different taxonomic levels within Brassicaceae. At the lowest

134 level, discrete changes in pollination traits have been reported between individuals of the same

135 species. In some species, this intraspecific phenotypic change is stable, like the gender

136 polymorphism $(27,28)$ or the adaptive floral colour polymorphism exhibited as a response to the

137 selective pressures exerted by certain pollinators $(29,30)$. In other species, discrete phenotypic

138 changes, although affecting pollination traits, seem to be just the consequence of some singular

139 and often unstable mutations affecting floral colour (31), the production of cleistogamous flowers

140 (32) or changes in the expression of homeotic genes that modify the formation of the floral organs

$141(33,34)$. We compiled information on the phenotypes of the different morphs in 34 polymorphic

142 species and calculated their values of intraspecific disparities (Figure 1a, Supplementary Data 2).

143 Although several polymorphic species showed considerable values of between-morph disparity,

144 they were significantly smaller than the disparity between spring and summer floral phenotypes of

$145 M$. arvensis $(Z$-score $=5.06, P<0.0001$, Figure 1 e, Table S2). We subsequently tested at what 
146 taxonomic level of Brassicaceae the disparity was equivalent to the plasticity-mediated disparity

147 observed in $M$. arvensis. For this, we calculated the floral disparity between pair of species

148 belonging to the genus Moricandia, the same genus, the same tribe, and different tribes

149 (Methods). The plasticity-mediated disparity of $M$. arvensis was significantly higher than the 150 disparity existing between the Moricandia species $(0.057 \pm 0.033$, mean \pm 1 s.e.m., $Z$-score $=$

$1516.27, P<0.0001)$ and between the species belonging to the same genus $(0.069 \pm 0.055, Z$-score

$152=3.51, P<0.0002$ ). It was marginally different from the disparity existing between species of

153 different genera but the same tribes $(0.150 \pm 0.085, Z$-score $=1.34, P=0.089)$ and it was

154 statistically similar to the disparity occurring between species belonging to different tribes $(0.167 \pm$

$1550.087, Z$-score $=1.11, P=0.133$, Figure $1 \mathrm{e})$. These findings suggest that phenotypic plasticity

156 allows $M$. arvensis individuals to jump in the morphospace longer distances than those granted

157 by some macroevolutionary processes.

159 We explored whether plasticity-mediated disparity may cause evolutionary divergence by

160 calculating the disparity of $M$. arvensis spring and summer phenotypes to their phylogenetic

161 ancestors. We retrieved 80 partial phylogenies from the literature and online repositories

162 (Methods), and assembled them into a supertree comprising 1876 taxa with information on their

163 floral phenotype. We then projected this supertree onto the morphospace to get a family-wide

164 phylomorphospace. We did not find evidence of phylogenetic constraints on morphospace

165 occupation since there was not significant phylogenetic signal for the position occupied by each

166 species (Multivariate Mantel test $=0.005, P=0.34$ ). The family-wide phylomorphospace was very

167 tangled (Figure 2a), with 492,751 intersections among lineages, suggesting the presence of many

168 events of floral divergence and convergence in the evolution of Brassicaceae pollination traits

169 (11). To calculate the disparity of the M. arvensis floral phenotypes to their ancestor, because

170 these analyses are sensitive to the tree topology and the inferred branch lengths (26), we used

171 four independent, time-calibrated phylogenies that included this species (Methods). The results

172 were consistent across phylogenies (Figure 2b,c; Tables S3). The spring phenotype did not

173 significantly diverge neither from the most recent common ancestor (MRCA) of Moricandia (Z-

174 score $=0.36, P=0.36)$ nor from its direct ancestor $(Z$-score $=-1.24, P=0.108)$. In contrast, the

175 summer phenotype of $M$. arvensis diverged significantly both from Moricandia MRCA (Z-score =

$1762.48, P=0.007)$ and from its direct ancestor $(Z$-score $=1.77, P=0.038)$. Hence, the summer

177 phenotype explores a region of the floral morphospace located out of its phylogenetic clade range

178 (Figure 2b). The ancestral disparity of the summer phenotype was even significantly higher than

179 the ancestral disparity of most other Brassicaceae species (Figure 2c). These findings suggest

180 that phenotypic plasticity causes the appearance of a novel phenotype that diverges radically

181 from its ancestors. 


\section{Plastic shifts in pollination niches}

184 Evolutionary divergence is mostly associated with the occupation of new ecological niches $(2,5)$.

185 Shifts between pollination niches are an important factor driving diversification in angiosperms

186 (35), including Brassicaceae $(36,37)$. We investigated whether the plasticity-mediated jump of $M$.

187 arvensis across the floral morphospace implicated the exploration of new pollination niches. We

188 compiled a comprehensive database comprising 456,031 visits done by over 800 animal species

189 from 19 taxonomical orders, 276 families and 43 functional groups to 554 Brassicaceae species

190 of 39 tribes (Methods, Supplementary Data 3). Afterwards, we identified the pollination niches of

191 these Brassicaceae plants and determined the niche of each M. arvensis floral phenotype by

192 means of bipartite modularity, a complex network tool that identifies the set of plants interacting

193 with similar groups of pollinators (18). This analysis showed that the network was significantly

194 modular (Modularity $=0.385, P<0.0001$ ) and identified eight different pollination niches

195 associated with different groups of pollinators (Figure 3a) located in different regions of the

196 morphospace (Figure 3b, $F=44.4, P<0.001, R^{2}=0.39$, Adonis test; Table S4).

Because different insects visited $M$. arvensis in spring and summer (Table S5), this plant species shifted between pollination niches seasonally (Figure 3b). During spring, $M$. arvensis belonged to a niche where most frequent pollinators were long-tongued bees, beeflies, and hawkmoths (pollination niche 5 in Figure 3a) (18). This pollination niche was also shared by the other Moricandia species (Figure 3c). In contrast, during summer M. arvensis belonged to a niche dominated by short-tongued bees (pollination niche 3 in Figure 3a). This niche shift was substantial. In fact, the overlap between the spring and summer pollinator niches of $M$. arvensis (Czekanowski overlap index $=0.35$ ) was significantly lower than the overlap between congeneric species of Brassicaceae $(0.57 \pm 0.42, Z$-score $=-0.51, P=0.003)$. This shift even entailed the divergence from the ancestral niche of the Moricandia lineage (pollination niche 5 according to a stochastic character mapping inference, Figure 3c). The within-individual floral plasticity allows $M$. arvensis to exploit a pollination niche that differs markedly from that exploited by its closest relatives and that have largely diverged from the ancestral niche.

213 A common consequence of adaptation to the same niche is convergent evolution (1, 2, 4). We

214 explored the possibility of convergent evolution of $M$. arvensis with other Brassicaceae sharing

215 either the spring niche (pollination niche 5) or the summer niche (pollination niche 3). We first

216 checked for the occurrence of convergence among species belonging to these pollination niches.

217 Because these analyses are extremely sensitive to the inferred branch lengths, we explored 
218 morphological convergence using three time-calibrated large (> $150 \mathrm{spp}$ ) phylogenies that

219 included M. arvensis (Methods). We tested for the occurrence of floral convergence between the

220 species belonging to each of those two pollination niches using three methods: the angle formed

221 by the phenotypic vectors connecting the position in the floral morphospace of each pair of

222 species with that of their most recent common ancestor (38), the difference in phenotypic

223 distances between convergent species and the maximum distances between all other lineages

224 (39), and the phenotypic similarity of the allegedly convergent species penalized by their

225 phylogenetic distance (Wheatsheaf index) (40). The three methods gave similar results, indicating

226 that floral convergence was frequent among the species belonging to any of the two studied

227 niches, irrespective of the method and the time-calibrated tree used (Table S6). These results

228 show that, despite the rampant generalization observed in the pollination system of Brassicaceae,

229 species interacting with similar pollinators converge phenotypically.

231 Once we determined the occurrence of convergence in these two pollination niches, we assessed

232 whether plasticity caused the evolution of morphological convergence in M. arvensis. To do so,

233 we first assessed the convergence region of Moricandia, the region that includes the lineages

234 converging morphologically to the Moricandia lineage. We found that this region included most

235 species of Moricandia, the spring phenotype of $M$. arvensis, and several clades belonging to

236 disparate tribes that interact with pollination niche 5, but excluded the summer phenotype of $M$.

237 arvensis (Figure 4, Table S7). Afterwards, we checked whether any of the two M. arvensis floral

238 phenotypes entered the region of the phylomorphospace defined by their pollination niches. We

239 used the C5 index, defined as the number of lineages that cross into the morphospace region of

240 interest from outside ${ }^{39}$. This index detected between two and six convergent events towards

241 pollination niche 5 depending on the phylogeny used (blue arrows in Figure 4a-c), but none was

242 associated with the spring phenotype of $M$. arvensis. In contrast, the C5 index consistently

243 detected that the summer phenotype of $M$. arvensis has converged with the species belonging to

244 the pollination niche 3 (red arrow in Figure 4d-f). Altogether, these analyses suggest that,

245 whereas the spring phenotype did not show any evidence of convergence, the summer

246 phenotype of $M$. arvensis has converged with other distant Brassicaceae exploiting the same

247 pollination niche.

\section{Conclusions}

251

252 Convergent selection exerted by efficient pollinators causes the evolution of similar suites of floral 253 traits in different plant species (41-44). Our study shows that plasticity can promote the rapid 
254 convergent evolution of floral traits, providing an additional explanation about how pollination

255 syndromes may evolve. Under this idea, changes in floral traits precede shifts in pollinators, as

256 frequently observed in generalist systems $(37,45)$. This may explain why many pollination

257 systems are evolutionarily labile, undergoing frequent shifts and evolve multiple times within the

258 same lineages by diverse evolutionary pathways $(35,46)$.

259

260 Morphological convergence is universally acknowledged to be the result of several genetic

261 mechanisms, such as independent mutations in different populations or species, polymorphic

262 genes or introgression (13). We provide in this study compelling evidence suggesting that

263 morphological convergence may also arise as a consequence of phenotypic plasticity. The role of

264 plasticity as a mechanism favouring quick responses of organisms to novel and rapidly changing

265 environments is already beyond doubt $(17,21,47,48)$. Its evolutionary consequences are more

266 debated though $(20,21,49,50)$. The 'plasticity-led evolution' hypothesis states that selection

267 acting on a plastic lineage may either boost its environmental sensitivity and trigger the origin of

268 polyphenisms or alternatively may promote the loss of plasticity and the canalization of the new

269 phenotype through genetic assimilation $(21,49)$. The related 'flexible stem' hypothesis of adaptive

270 radiation suggests that when a plastic lineage repeatedly colonizes similar niches, the multiple

271 phenotypes fixed by genetic assimilation could converge among them giving rise to a collection of

272 phylogenetically related convergent morphs (16, 50,51). Our comprehensive study complements

273 these hypotheses by suggesting that plasticity-mediated convergence may even evolve without

274 the existence of basal flexible lineages. Rather, it can occur when plasticity evolving in otherwise

275 non-plastic lineages promotes the colonization of a niche previously occupied by unrelated

276 species. Under these circumstances, contrary to what it is predicted by the previous hypotheses,

277 plasticity-mediated convergence is not circumscribed to phylogenetic-related species arising from

278 a common stem lineage. This overlooked role of phenotypic plasticity may contribute to explain

279 the ubiquity of morphological convergence in nature.

\section{Materials and Methods}

284 Floral traits. We recorded from the literature 31 floral traits in 3140 Brassicaceae plant species 285 belonging to 330 genera and 51 tribes (Supplementary Data 1). All these traits have been proven 286 to be important for the interaction with pollinators (Table S8). These traits were: (1) Plant height;

287 (2) Flower display size; (3) Inflorescence architecture; (4) Presence of apetalous flowers; (5)

288 Number of symmetry axes of the corolla; (6) Orientation of dominant symmetry axis of the corolla;

289 (7) Corolla with overlapped petals; (8) Corolla with multilobed petals; (9) Corolla with visible 
290 sepals; (10) Petal length; (11) Sepal length; (12) Asymmetric petals; (13) Petal limb length; (14)

291 Length of long stamens; (15) Length of short stamens; (16) Stamen dimorphism; (17)

292 Tetradynamous condition; (18) Visible anthers; (19) Exserted stamens; (20) Number of stamens;

293 (21) Concealed nectaries; (22) Petal carotenoids; (23) Petal anthocyanins; (24) Presence of

294 bullseyes; (25) Presence of veins in the petals; (26) Coloured sepals; (27) Relative attractiveness

295 of petals versus sepals; (28) Petal hue; (29) Petal colour as b CIELAB; (30) Sepal hue; (31) Sepal

296 colour as $b$ CIELAB. A detailed definition and description of these traits and their states is

297 provided in Key Resource Table 1, whereas the original references used to determine the states

298 of each trait per plant species is provided in Supplementary Data 1.

300 Family-wide floral morphospace. Using the original multidimensional trait-species matrix, we

301 built a floral morphospace. For this, we reduced the high-dimensional matrix of floral traits to a

302 two-dimensional space using an ordination technique (25). Because the set of floral traits

303 included in this study were quantitative, semi-quantitative and qualitative, we used ordination

304 techniques based on dissimilarity values. For this, we first constructed a pairwise square distance

305 matrix of length equal to the number of Brassicaceae species included in the analysis $(n=3140)$.

306 We used the Gower distance, the number of mismatched traits over the number of shared traits.

307 This dissimilarity index is preferable to the raw Euclidean distance when there are discrete and

308 continuous traits co-occurring in the same dataset (52).

309 We reduced the dimensionality of this phenotypic matrix by projecting it in a two-dimensional

310 space. For this, to ensure an accurate description of the distribution of the species in the

311 morphospace, we first run a principal coordinate analysis (PCOA), a technique providing a

312 Euclidean representation of a set of objects whose relationship is measured by any dissimilarity

313 index. We corrected for negative eigenvalues using the Cailliez procedure (25). Afterwards, we

314 used this metric configuration as the initial configuration to run a non-metric multidimensional

315 scaling (NMDS) algorithm (25), a method that will further optimise the sample distribution so as

316 more variation in species composition is represented by fewer ordination axes. Unlike methods

317 that attempt to maximise the variance or correspondence between objects in an ordination,

318 NMDS attempts to represent, as closely as possible, the pairwise dissimilarity between objects in

319 a low-dimensional space. NMDS is a rank-based approach, where the original distance data is

320 substituted with ranks, preserving the ordering relationships among species (25). Objects that are

321 ordinated closer to one another are likely to be more similar than those further apart (53). This

322 method is more robust than distance-based methods when the original matrix includes variables

323 of contrasting nature. However, NMDS is an iterative algorithm that can fail to find the optimal

324 solution. We decreased the potential effect of falling in local optima by running the analysis with

3255000 random starts and iterating each run $1 \times 10^{6}$ times (54). The NMDS was run using a 
326 monotone regression minimizing the Kruskal's stress-1 (55, 56), and compared each solution

327 using Procrustes analysis, retaining that with the lowest residual. Because many species did not

328 share trait states, a condition complicating ordination, we used stepacross dissimilarities, a

329 function that replaces dissimilarities with shortest paths stepping across intermediate sites while

330 regarding dissimilarities above a threshold as missing data (57). Furthermore, we used weak tie

331 treatment, allowing equal observed dissimilarities to have different fitted values. The scores of the

332 species in the final ordination configuration were obtained using weighted averaging. We checked

333 if the reduction in dimensionality maintained the between-species relationship by checking the

334 stress of the resulting ordination and finding goodness of fit measure for points in nonmetric

335 multidimensional scaling (54). Both PCoA and NMDS ordinations were done using the R package

336 vegan (58) and ecodist (59). It is important to note that, although the transfer function from

337 observed dissimilarities to ordination distances is non-metric, the resulting NMDS configuration is

338 Euclidean and rotation-invariant (60).

340 Morphological Disparity. Because we were interested in describing the position of the species

341 in the floral morphospace, we calculated the morphological disparity using indices related to the

342 distance between elements $(26,61)$. We first determined the absolute position of each of the

343 Brassicaceae species in the morphospace by calculated their Euclidean distance with the overall

344 centroid of the morphospace (61). The disparity between the spring and summer phenotype of $M$.

345 arvensis was also calculated as their Euclidean distance in the floral morphospace. We then

346 calculated the pairwise disparities between all species included in our analysis, between the

347 different morphs of the polymorphic species considered here (Supplementary Data 2), between

348 the species of the genus Moricandia, between species of the same genus, between species of

349 different genera but same tribe and between species of different tribes. These disparity values

350 were calculated using the function dispRity of the R package dispRity using the command

351 centroid (62). We checked whether the disparity between spring and summer M. arvensis

352 phenotypes was significantly different from the disparities of each of these sets of species using

$353 \quad Z$-score tests.

354

355 Family-wide phylogeny. We retrieved 80 phylogenetic trees from the literature and from the

356 online repositories TreeBase (Table S9). All trees were downloaded in nexus format. The

357 taxonomy of the species included in each tree was checked and updated using the species

358 checklist with accepted names provided by Brassibase (https://brassibase.cos.uni-heidelberg.de/)

$359(7,23,63)$. All trees were converted to TreeMan format (64) and concatenated into a single

360 TreeMen file that was then converted into a multiPhylo class. Afterward, we estimated a

361 supertree from this set of trees. Because trees did not share the same taxa, we used the Matrix 
362 representation parsimony method (65). To make this supertree more accurate, it was re-

363 constructed using as backbone phylogeny the tree provided by Walden et al. (7). We removed

364 from the supertree those species without information on floral phenotype, resulting in a tree with

3651876 taxa. Because the original trees used to assemble this supertree where very

366 heterogeneous, this supertree was not dated. We finally rooted the supertree using several

367 species belonging to the sister families Capparaceae and Cleomaceae (66). All phylogenetic

368 manipulations were performed using the $\mathrm{R}$ libraries treebase (67), ape (68), treeman (64),

369 phangorn (69) and phytools (70).

370 We tested whether the position of the Brassicaceae species in the morphospace was

371 associated with the phylogenetic relationship by assessing the phylogenetic signal of the

372 morphospace position. This analysis was performed by means of a multivariate Mantel test, using

373 the pairwise disparity (the Euclidean distance between species in the family-wide morphospace)

374 as a morphological distance and the patristic distances between pairs of tips of the supertree as

375 the phylogenetic distance (71). The correlation method used was Pearson and the statistical

376 significance was found after bootstrapping 999 times the analysis (25). The test was done using

377 the $\mathrm{R}$ libraries vegan (58) and ecodist (59).

379 Family-wide phylomorphospace. We reconstructed a family-wide phylomorphospace by

380 projecting the phylogenetic relationships provided by the supertree into the floral morphospace.

381 The ancestral character estimation of morphospace coordinate values for each internal tree node

382 was done using maximum likelihood. For this, we used the function fastAnc in phytools. This

383 function performs fast estimations of the $M L$ ancestral states for continuous traits by re-rooting

384 the tree at all internal nodes and computing the contrasts state at the root each time (70).

385 We counted the number of intersections between lineages as a measurement of the

386 disorder of the phylomorphospace and evidence of the mode of evolution of the phenotypes (11).

387 For this, we used $\mathrm{R}$ codes provided in Ref 11 . We compared the observed number of crossings

388 with those expected under several modes of evolution. For this, we counted the number of

389 intersections in 10 simulated sets of species with floral phenotypes following Brownian Motion,

390 Ornstein Uhlenbeck and Early Burst modes of evolution. All simulations were done using as

391 backbone tree the family-wide supertree and considering 1875 species, and by means of the

392 command mvSIM in mvMORPH(72).

393

394 Morphological divergence of the plastic phenotypes. Divergence in floral phenotype was

395 estimated by calculating the disparity of Moricandia arvensis and the rest of Brassicaceae

396 species from their ancestors. We first determined the floral phenotype of the Most Recent

397 Common Ancestor (MRCA) using the projection of a recent time-calibrated phylogeny made for 
398 the genus Moricandia (73) into the above-described phylomorphospace. We used this phylogeny

399 because it is the only one including all the species of the genus. Once we inferred the coordinates

400 of the MRCA in the morphospace, we calculated the disparity of all the Moricandia species and

401 the two plastic phenotypes of $M$. arvensis to it. Afterwards, we calculated the divergence of the

402 two plastic phenotypes from the direct ancestor of $M$. arvensis. This analysis was done for the

403 family-wide supertree and for any of the four time-calibrated phylogenies included in our dataset

404 that had Moricandia species (73-76). In addition, we calculated the divergence from the direct

405 ancestors of the rest of Brassicaceae species included in these four phylogenies and in the rest

406 of the time-calibrated trees included in our dataset (Table S9). All floral divergences were

407 calculated using the command ancestral.dist of the function dispRity in the R package dispRity

408 (62).

409

410 Pollinator Database. We have compiled a massive database including 21,212 records

411 comprising 455,014 visits done by over 800 animal species from 19 taxonomical orders, 276

412 families and 43 functional groups to 554 Brassicaceae species belonging to 39 tribes

413 (Supplementary Data 3). Information is coming from literature, personal observation, online

414 repositories and personal communication of several colleagues. The source of information is

415 indicated in the database (Supplementary Data 3, Table S10). In those species studied by us

416 (coded as UNIGEN data origin in the Supplementary Data 3), we conducted flower visitor counts

417 in 1-16 populations per plant species. We visited the populations during the blooming peak,

418 always at the same phenological stage and between 11:00 am and 5:00 pm. In these visits, we

419 recorded the insects visiting the flowers for two hours without differentiating between individual

420 plants. Insects were identified in the field, and some specimens were captured for further

421 identification in the laboratory. We only recorded those insects contacting anthers or stigma and

422 doing legitimate visits at least during part of their foraging at flowers. We did not record those

423 insects only eating petals or thieving nectar without doing any legitimate visit. The information

424 obtained from the literature and online repositories (coded as LITERATURE data origin in the

425 Supplementary Data 3) includes records done during ecological studies, taxonomical studies and

426 naturalistic studies. The reference of every record is included in the dataset. The plant species

427 included in our network do not coexist, implying that this is a clade-oriented network rather than

428 an ecological network (77).

429

430 Spatial distribution of pollinator groups. We tested the autocorrelation across the

431 morphospace in the abundance of the functional groups using a multivariate Mantel test. The

432 correlation method used was Pearson, and the statistical significance was found after

433 bootstrapping 999 times the analysis (25). The test was done using the $\mathrm{R}$ libraries vegan (58). 
435 Pollination niches. In plant species interacting with a diverse assemblage of pollinators, like

436 those included in this study, many pollinator species interact with the flowers in a similar manner,

437 have similar effectiveness and exert similar selective pressures and are thus indistinguishable for

438 the plant $(46,78)$. These pollinators are thus grouped into functional groups, which are the

439 relevant interaction units in generalised systems $(46,78,79)$. We thereby grouped all pollinators

440 visiting the Brassicaceae species using criteria of similarity in body length, proboscis length,

441 morphological match with the flower, foraging behaviour, and feeding habits (46, 78, 79). Table

442 S11 describes the 43 functional groups used in this study. Supplementary Data 4 shows the

443 species with an autogamous pollination system.

445 We determined the occurrence of different pollination niches in our studied populations and 446 seasons using bipartite modularity, a complex-network metric. Modularity has proven to be a

447 good proxy of interaction niches both in ecological networks, those included coexisting species or

448 population, as well as in clade-oriented network, those including species with information coming

449 from disparate and contrasting sources (77). We constructed a weighted bipartite network,

450 including pollinator data of four populations during the spring and summer flowering. In this

451 network, we pooled the data from the different individuals in a population and did not consider the

452 time difference involved in sampling across different species. We removed all plant species with

453 less than 20 visits. We subsequently determined the modularity level in this weighted bipartite

454 network by using the QuanBiMo algorithm (80). This method uses a Simulated Annealing Monte-

455 Carlo approach to find the best division of populations into modules. A maximum of $10^{10} \mathrm{MCMC}$

456 steps with a tolerance level $=10^{-10}$ was used in 100 iterations, retaining the iterations with the

457 highest likelihood value as the optimal modular configuration. We tested whether our network was

458 significantly more modular than random networks by running the same algorithm in 100 random

459 networks, with the same linkage density as the empirical one (81). Modularity significance was

460 tested for each iteration by comparing the empirical versus the random modularity indices using a

$461 Z$-score test (80). After testing the modularity of our network, we determined the number of

462 modules (82). We subsequently identified the pollinator functional groups defining each module

463 and the plant species ascribed to each module. Modularity analysis was performed using the $\mathrm{R}$

464 package bipartite 2.0 (83). We quantified the niche overlap between all pair of Brassicaceae

465 species using the Czekanowski index of resource utilization, an index that measures the area of

466 intersection of the resource utilization histograms of each species pair (84). This index was

467 calculated using the function niche.overlap in the R package spaa (85). 
469 Estimation of ancestral values of pollination niches. The ancestral states of the pollination

470 niche was inferred for the Moricandia lineage by simulate stochastic character mapping of

471 discrete traits with Bayesian posterior probability distribution (86, 87). Three models of character

472 evolution ("ER" - Equal Rates; "SYM" - symmetric; and "ARD" - All Rates Different) were first

473 evaluated using the fitDiscrete function of the R package Geiger (88). The best model was

474 selected using the Akaike Information Criterion (AIC) and used for stochastic character mapping.

475 The posterior distribution of the transition rate matrix was determined using a Markov chain

476 Monte Carlo (MCMC) simulation, and the stochastic mapping was simulated 100 times.

477 Stochastic character mapping was performed using the make.simmap function and a plot of

478 posterior probabilities were mapped using the describe.simmap function in R package 'phytools

479 (70).

480

481 Morphological convergence. To explore morphological convergence, we reconstructed the

482 ancestral states of the species belonging to these two pollination niches and tested for each niche

483 whether the species were morphologically more similar to each other than expected by their

484 phylogenetic relationship (39, 40). We used three different approaches to detect morphological

485 convergence, one based on comparing phenotypic and phylogenetic distances (39) and the other

486 based on comparing the angles formed by two tested clades from their most recent common

487 ancestor with the expected angle according to null evolutionary models (38). Because all these

488 analyses are sensitive to the number of tips in the phylogeny and the inferred branch lengths, we

489 tested for the occurrence of morphological convergence using three independent, time-calibrated

490 phylogenies including more than 45 species (74-76).

491 Under the first approach, we calculated both distance- and frequency-based measures of

492 convergence (39). Distance-based measures (C1-C4) are calculated between two lineages

493 relative to their distance at the point in evolutionary history where the two lineages were

494 maximally dissimilar. C1 specifically measures the proportion of phenotypic distance closed by

495 evolution, ranging from 0 to 1 (where 1 indicates complete convergence). To calculate $\mathrm{C} 1$,

496 ancestral states are reconstructed (via a Brownian motion model of evolution) for two or more

497 putatively convergent lineages, back to their most recent common ancestor. The maximum

498 phenotypic distance between any pair of ancestors (Dmax) is calculated, and compared with the

499 phenotypic distance between the current putatively convergent taxa (Dtip). The greater the

500 difference between Dmax and Dtip, the higher the index. C2 is the raw value of the difference

501 between the maximum and extant distance between the two lineages. C3 is C2 scaled by the

502 total evolution (sum of squared ancestor-to-descendant changes) between the two lineages. C4

503 is $\mathrm{C} 2$ scaled by the total evolution in the whole clade. These four measures quantify incomplete

504 convergence in multidimensional space. Finally, C5, the frequency-based measure, quantifies 
505 and reports the number of convergent events where lineages evolve into a specific region of

506 morphospace (crossing it from outside). C5 sums the number of times through the evolution of a

507 clade that lineages evolve into a given region of phenotypic space. C5 is the number of focal taxa

508 that reside within a limited but convergent region of a phylomorphospace (the phylogenetic

509 connections between taxa represented graphically in a plot of morphological space). The

510 significance of $\mathrm{C} 1-\mathrm{C} 5$ was found by running 1000 simulations for each comparison using

511 Brownian-Motion on a variance-covariance matrix based on data-derived parameters, with

512 convergence measures for each simulation calculated to determine if the observed $C$ value is

513 greater than expected by chance. A priori focal groups forming the basis of convergence tests

514 were the same niche categorizations used in OUwie analyses. These analyses were performed

515 using the R package convevol (89).

516 The second approach to measure convergence was based on comparing the angles

517 formed by two tested clades from their most recent common ancestor with the expected angle

518 according to null evolutionary models (38). Under the "state case", search.conv computes the

519 mean angle over all possible combinations of species pairs using one species per state. Each

520 individual angle is divided by the patristic distance between the species. Significance is assessed

521 by contrasting this value with a family of 1,000 random angles obtained by shuffling the state

522 across the species (38). These analyses were performed using the R package RRphylo (90).

523 The third approach to measure convergence used the Wheatleaf metric (40). This index

524 generates phenotypic (Euclidean) distances from any number of traits across species and

525 penalizes them by phylogenetic distance before investigating similarity (in order to weight close

526 phenotypic similarity higher for distantly related species). It uses an a priori designation of

527 convergent species, which are defined as species belonging to a niche for which the traits are

528 hypothesized to converge. The method then calculates a ratio of the mean (penalized) distances

529 between all species to the mean (penalized) distances between allegedly convergent species.

530 The index detects if convergent species diverge more in phenotypic space from the non-

531 convergent species and show a tighter clustering to each other (40). The significance of this index

532 was found by comparing the empirical values of the index with a distribution of simulated indices

533 obtained running 5000 bootstrap simulations. These analyses were performed using the $\mathrm{R}$

534 package windex (91).

538 Authors thank Raquel Sánchez, Angel Caravantes, Isabel Sánchez Almazo, María José

539 Jorquera, and Iván Rodríguez Arós for helping us during several phases of the study. We also

540 thank all contributors to the pollinator database (Table S10) for kindly sending us unpublished 
541 information on Brassicaceae floral visitors. This research is supported by grants from the Spanish

542 Ministry of Science, Innovation and Universities (CGL2015-63827-P, CGL2017-86626-C2-1-P,

543 CGL2017-86626-C2-2-P, UNGR15-CE-3315), Junta de Andalucía (P18-FR-3641, IE19_238

544 EEZA CSIC), LIFE18 GIE/IT/000755, and Xunta de Galicia (CITACA), including EU FEDER

545 funds. This is a contribution to the Research Unit Modeling Nature, funded by the Consejería de

546 Economía, Conocimiento, Empresas y Universidad, and European Regional Development Fund

547 (ERDF), reference SOMM17/6109/UGR.

548

\section{Competing interests}

550 The authors declare no competing interests.

\section{References}

554 1. G. R. McGhee, Convergent Evolution: Limited Forms Most Beautiful. MIT Press, Cambridge (2011). ISBN:9780262016421

2. J. B. Losos, Convergence, adaptation, and constraint. Evolution 65, 1827-1840 (2011). doi:10.1111/j.1558-5646.2011.01289.x

3. S. C. Morris, Life's solution: Inevitable Humans in a Lonely Universe. Cambridge University Press, Cambridge (2003). ISBN:9780521603256

4. T. Pearce, Convergence and parallelism in evolution: a Neo-Gouldian account. Br. J. Philos. Sci. 63, 429-448 (2011). doi:10.1093/bjps/axr046

5. D. Schluter, The Ecology of Adaptive Radiation. Oxford Univ. Press, Oxford, U.K. (2000) ISBN:9780198505228

6. P. Nosil, Ecological Speciation. Oxford Univ. Press, Oxford, U.K. (2012) ISBN:9780199587100

7. N. Walden, D. A. German, E. M. Wolf, M. Kiefer, P. Rigault, X. C. Huang, C. Kiefer, R. Schmickl, A. Franzke, B. Neuffer, K. Mummenhoff, Nested whole-genome duplications

574 10.K. O. Winemiller, D. B. Fitzgerald, L. M. Bower, E. R. Pianka, Functional traits, convergent 575 evolution, and periodic tables of niches. Ecol. Lett. 18, 737-751 (2015). doi:10.1111/ele.12462 
576 11.C. T. Stayton, Are our phylomorphospace plots so terribly tangled? An investigation of disorder in data simulated under adaptive and nonadaptive models. Curr. Zool. 66, 565-574 (2020). doi:10.1093/cz/zoaa045

12.A. L. Pigot, C. Sheard, E. T. Miller, T. P. Bregman, B. G. Freeman, U. Roll, N. Seddon, C. H. Trisos, B. C. Weeks, J. A. Tobias, Macroevolutionary convergence connects morphological form to ecological function in birds. Nature Ecol. Evol. 4, 230-239 (2020). doi:10.1038/s41559-019-1070-4

13.D. L. Stern, The genetic causes of convergent evolution. Nat. Rev. Genet. 14, 751-764 (2013). doi:10.1038/nrg3483

14.E. B. Rosenblum, C. E. Parent, E. E. Brandt, The molecular basis of phenotypic convergence. Annu. Rev. Ecol. Evol. Syst. 45, 203-226 (2014). doi:10.1146/annurev-ecolsys-120213091851

15.P. A. Christin, D. M. Weinreich, G. Besnard, Causes and evolutionary significance of genetic convergence. Trends Genet. 26, 400-405 (2010). doi:10.1016/j.tig.2010.06.005

16.M. J. West-Eberhard, Developmental Plasticity and Evolution. Oxford Univ. Press, New York, (2003). ISBN: 9780195122343

17.S. Sultan, Organism and Environment: Ecological development, Niche construction, and Adaption. Oxford Univ. Press, New York, (2015). ISBN:9780199587063

18.J. M. Gómez, F. Perfectti, C. Armas, E. Narbona, A. González-Megías, L. Navarro, L. DeSoto, R. Torices, Within-individual phenotypic plasticity in flowers fosters pollination niche shift. Nature Comm. 11, 4019 (2020). doi:10.1038/s41467-020-17875-1

19.V. Susoy, E. J. Ragsdale, N. Kanzaki, R. J. Sommer, Rapid diversification associated with a macroevolutionary pulse of developmental plasticity, eLife 4, e05463 (2015). doi:10.7554/eLife.05463

20.N. A. Levis, D. W. Pfennig, Evaluating 'plasticity-first 'evolution in nature: key criteria and empirical approaches. Trends Ecol. Evol. 31, 563-574 (2016). doi:10.1016/j.tree.2016.03.012

21.R. J. Sommer, Phenotypic plasticity: from theory and genetics to current and future challenges. Genetics 215, 1-13 (2020). doi:10.1534/genetics.120.303163

22.M. A. Koch, D. A. German, M. Kiefer, A. Franzke, Database taxonomics as key to modern plant biology. Trends Plant Sci. 23, 4-6 (2018). doi:10.1016/j.tplants.2017.10.005 Franzke, K. Mummenhoff, A. Stamatakis, M.A. Koch, BrassiBase: introduction to a novel knowledge database on Brassicaceae evolution. Plant Cell Physiol. 55, e3-e3 (2014). doi:10.1093/pcp/pct158 http://www.theplantlist.org/1.1/browse/A/Brassicaceae/ (2013). 
612 25.P. Legendre, L. Legendre, Numerical Ecology. Elsevier, Oxford (2012). ISBN:9780080523170

613 26.T. Guillerme, N. Cooper, S. L. Brusatte, K. E. Davis, A. L. Jackson, S. Gerber, A. Goswami, K. 614 Healy, M. J. Hopkins, M. E. Jones, G. T. Lloyd, Disparities in the analysis of morphological disparity. Biol. Lett. 16, 20200199 (2020). doi:10.1098/rsbl.2020.0199

27.M. Méndez, J. M. Gómez, Phenotypic gender in Hormathophylla spinosa (Brassicaceae), a perfect hermaphrodite with tetradynamous flowers, is variable. Plant Syst. Evol. 262, 225-23 (2006). doi:10.1007/s00606-006-0462-5

28. V. L. Soza, V. Le Huynh, V. S. Di Stilio, Pattern and process in the evolution of the sole dioecious member of Brassicaceae. EvoDevo 5, 42 (2014). doi:10.1186/2041-9139-5-42 Mediterranean Basin: occurrence, maintenance and implications for speciation. Plant Biol. 20, 8-20 (2018). doi:10.1111/plb.12575.

30.C. A. Dick, J. Buenrostro, T. Butler, M. L, Carlson, D. J. Kliebenstein, J. B. Whittall, Arctic mustard flower color polymorphism controlled by petal-specific downregulation at the threshold of the anthocyanin biosynthetic pathway. PLoS One 6, e18230 (2011). doi:10.1371/journal.pone.0018230

\section{B. Zhang, C. Liu, Y. Wang, X. Yao, F. Wang, J. Wu, G. J. King, K. Liu, Disruption of a} carotenoid cleavage dioxygenase 4 gene converts flower colour from white to yellow in

$$
\text { Brassica species. New Phytol. 206, 1513-1526 (2015). doi:10.1111/nph.13335 }
$$

32.S. Faisal, Y. Guo, S. Zang, B. Cao, G. Qu, S. Hu, Morphological and genetic analysis of a cleistogamous mutant in rapeseed (Brassica napus L.). Genet. Resour. Crop Evol. 65, 397403 (2018). doi:10.1007/s10722-017-0598-x

33.G. Theissen, Homeosis of the angiosperm flower: studies on three candidate cases of saltational evolution. Palaeodiversity 3, 131-139 (2010).

34.M. V. Byzova, J. Franken, M. G. Aarts, J. de Almeida-Engler, G. Engler, C. Mariani, M. M. V. L. Campagne, G. C. Angenent, Arabidopsis STERILE APETALA, a multifunctional gene

645 37.J. M. Gómez, F. Perfectti, J. Lorite, The role of pollinators in floral diversification in a clade of 646 generalist flowers. Evolution 69, 863-878 (2015). doi:10.1111/evo.12632 
647

648

649

650

651

652

653

654

655

656

657

658

659

660

661

662

663

664

665

666

667

668

669

670

671

672

673

674

675

676

677

678

679

680

681

38.S. Castiglione, C. Serio, D. Tamagnini, M. Melchionna, A. Mondanaro, M. Di Febbraro, A. Profico, P. Piras, F. Barattolo, P. Raia, A new, fast method to search for morphological convergence with shape data. PloS One 14: e0226949 (2019). doi:10.1371/journal.pone.0226949

39.C. T. Stayton, The definition, recognition, and interpretation of convergent evolution, and two new measures for quantifying and assessing the significance of convergence. Evolution 69, 2140-2153 (2015). doi:10.1111/evo.12729

40.K. Arbuckle, C. M. Bennett, M. P. Speed, A simple measure of the strength of convergent evolution. Methods Ecol. Evol. 5, 685-693 (2014). doi:10.1111/2041-210X.12195

41.K. Faegri, L. Van Der Pijl, Principles of Pollination Ecology. Elsevier, Oxford (1980). ISBN:9780080164212

42.A. S. Dellinger, Pollination syndromes in the 21 st century: where do we stand and where may we go?. New Phytol. 228, 1193-1213 (2020). doi:10.1111/nph.16793

43.R. D. Phillips, R. Peakall, T. van der Niet, S. D. Johnson, Niche perspectives on plantpollinator interactions. Trends Plant Sci. 25, 779-793 (2020).

doi:10.1016/j.tplants.2020.03.009.

44.C. A. Wessinger, L. C. Hileman, Parallelism in flower evolution and development. Annu. Rev. Ecol. Evol. Syst. 51, 387-408 (2020). doi:10.1146/annurev-ecolsys-011720-124511

45.J. D. Thomson, P. Wilson, Explaining evolutionary shifts between bee and hummingbird pollination: convergence, divergence, and directionality. Int. J. Plant Sci. 169, 23-38 (2008). doi:10.1086/523361

46.J. M. Gómez, F. Perfectti, M. Abdelaziz, J. Lorite, A. J. Muñoz-Pajares, J. Valverde, Evolution of pollination niches in a generalist plant clade. New Phytol. 205, 440-453 (2015). doi:10.1111/nph.13016

47.E. C. Snell-Rood, M. E. Kobiela, K. L. Sikkink, A. M. Shepherd, Mechanisms of plastic rescue in novel environments. Annu. Rev. Ecol. Evol. Syst. 49, 331-354 (2018). doi:10.1146/annurevecolsys-110617-062622

48.R. J. Fox, J. M. Donelson, C. Schunter, T. Ravasi, J. D. Gaitán-Espitia, Beyond buying time: the role of plasticity in phenotypic adaptation to rapid environmental change. Phil. Trans. $R$. Soc. B 374, 20180174 (2019). doi:10.1098/rstb.2018.0174

49.N. A. Levis, D. W. Pfennig, Plasticity-led evolution: evaluating the key prediction of frequencydependent adaptation. Proc. Biol. Sci. 286, 20182754 (2019). doi:10.1098/rspb.2018.2754

50.M. R. Warner, L. Qiu, M. J. Holmes, A. S. Mikheyev, T. A. Linksvayer, Convergent eusocial evolution is based on a shared reproductive groundplan plus lineage-specific plastic genes. Nature Comm. 10, 1-11 (2019). doi:10.1038/s41467-019-10546-w 
51.R. F. Schneider, A. Meyer, How plasticity, genetic assimilation and cryptic genetic variation may contribute to adaptive radiations. Mol. Ecol. 26, 330-350 (2017). doi:10.1111/mec.13880

52.T. Guillerme, N. Cooper, Time for a rethink: time sub - sampling methods in disparity -through time analyses. Palaeontology 61, 481-493 (2018). doi:10.1111/pala.12364

53.P. Legendre, D. Borcard, P. R. Peres-Neto, Analyzing beta diversity: Partitioning the spatial variation of community composition data. Ecol. Monogr. 75, 435-450 (2005). doi:10.1890/050549

54.P. Mair, I. Borg, Rusch T. Goodness-of-fit assessment in multidimensional scaling and unfolding. Multivar. Behav. Res. 51, 772-789 (2016). doi:10.1080/00273171.2016.1235966.

55.J. B. Kruskal, Multidimensional scaling by optimizing goodness-of-fit to a nonmetric hypothesis. Psychometrika 29, 1-28 (1964).

56.J. B. Kruskal, Nonmetric multidimensional scaling: a numerical method. Psychometrika 29, 115-129 (1964).

57.G. De'ath, Extended dissimilarity: a method of robust estimation of ecological distances from high beta diversity data. Plant Ecol. 144, 191-199 (1999). doi:10.1023/A:1009763730207 Simpson, P. Solymos, M. H. H. Stevens, H. Wagner, 2013 Package 'vegan'. Community ecology package, version 2, 1-295 https://cran.r-project.org, https://github.com/vegandevs/vegan (2019)

59.S. C. Goslee, Urban, D. L The ecodist package for dissimilarity-based analysis of ecological data. J. Stat. Softw. 22, 1-19 (2007). doi:10.18637/jss.v022.i07

60.J. Oksanen, Vegan: an introduction to ordination. URL http://cran. r-project. org/web/packages/vegan/vignettes/introvegan.pdf (2020).

61.T. Guillerme, M. N. Puttick, A. E. Marcy, V. Weisbecker, Shifting spaces: Which disparity or dissimilarity measurement best summarize occupancy in multidimensional spaces?. Ecol. Evol. 10, 7261-7275 (2020). doi:10.1002/ece3.6452

62.T. Guillerme, dispRity: a modular R package for measuring disparity. Methods Ecol. Evol. 9, 1755-1763 (2018). doi:10.1111/2041-210X.13022

63.M. A. Koch, M. Kiefer, D.A. German, I.A. Al-Shehbaz, A. Franzke, K. Mummenhoff, R. Schmickl, BrassiBase: Tools and biological resources to study characters and traits in the Brassicaceae - version 1.1. Taxon 61, 1001-1009 (2012). doi:10.1002/tax.615007

64.D. J., Bennett, M. D., Sutton, S. T. Turvey, Treeman: an R package for efficient and intuitive manipulation of phylogenetic trees. BMC Res. Notes 10, 30 (2017). doi:10.1186/s13104-0162340-8

65.M. A. Ragan, Phylogenetic inference based on matrix representation of trees. Mol. Phylogenetics Evol. 1, 53-58 (1992). doi:10.1016/1055-7903(92)90035-F 
66.S. Bayat, M. E. Schranz, E. H. Roalson, J. C. Hall, Lessons from Cleomaceae, the sister of crucifers. Trends Plant Sci. 23, 808-821 (2018). doi:10.1016/j.tplants.2018.06.010.

67.C. Boettiger, D. Temple Lang, Treebase: an R package for discovery, access and manipulation of online phylogenies. Methods Ecol. Evol. 3, 1060-1066 (2012). doi:10.1111/j.2041-210X.2012.00247.x

68.E., Paradis, K. Schliep, ape 5.0: an environment for modern phylogenetics and evolutionary analyses in R. Bioinformatics 35, 526-528 (2019). doi:10.1093/bioinformatics/bty633

69.K. Schliep, phangorn: phylogenetic analysis in R. Bioinformatics 27, 592-593 (2011). doi:10.1093/bioinformatics/btq706

70.L. J. Revell, phytools: an R package for phylogenetic comparative biology (and other things). Methods Ecol. Evol. 3, 217-223 (2012). doi:10.1111/j.2041-210X.2011.00169.x

71.O. J. Hardy, S. Pavoine, Assessing phylogenetic signal with measurement error: a comparison of Mantel tests, Blomberg et al.'s K, and phylogenetic distograms. Evolution 66, 2614-2621 (2012). doi:10.1111/j.1558-5646.2012.01623.x

72.J. Clavel, G. Escarguel, G. Merceron, mvMORPH: an R package for fitting multivariate evolutionary models to morphometric data. Methods Ecol. Evol. 6, 1311-1319 (2015). doi:10.1111/2041-210X.12420

73.F. Perfectti, J. M. Gómez, A. González-Megías, M. Abdelaziz, J. Lorite, Molecular phylogeny and evolutionary history of Moricandia DC (Brassicaceae). PeerJ 5, e3964 (2017). doi:10.7717/peerj.3964

74.S. A. Smith, J. W. Brown, Constructing a broadly inclusive seed plant phylogeny. Am. J. Bot. 105, 302-314 (2018). doi:10.1002/ajb2.1019

75.M. L. Gaynor, J. Ng, R. G. Laport, Phylogenetic structure of plant communities: are polyploids distantly related to co-occurring diploids?. Frontiers Ecol. Evol. 6, 52 (2018). doi:10.3389/fevo.2018.00052

76.X.-C. Huang, D. A. German, M. A. Koch, Temporal patterns of diversification in Brassicaceae demonstrate decoupling of rate shifts and mesopolyploidization events. Ann. Bot. 125, 29-47 (2019). doi:10.1093/aob/mcz123

77.J. M. Gómez, M. Verdú, F. Perfectti, Ecological interactions are evolutionarily conserved across the entire tree of life. Nature 465, 918-921 (2010). doi:10.1038/nature09113

78.C. B. Fenster, W. S. Armbruster, P. Wilson, M. R. Dudash, J. D. Thomson, Pollination syndromes and floral specialization. Annu. Rev. Ecol. Evol. Syst. 35, 375-403 (2004). doi:10.1146/annurev.ecolsys.34.011802.132347

79.J. M. Gómez, R. Torices, J. Lorite, C. P. Klingenberg, F. Perfectti, The role of pollinators in the evolution of corolla shape variation, disparity and integration in a highly diversified plant family with a conserved floral bauplan. Ann. Bot. 117, 889-904 (2016). doi:10.1093/aob/mcv194 
754 80.C. F. Dormann, R. Strauss, A method for detecting modules in quantitative bipartite networks. Methods Ecol. Evol. 5, 90-98 (2014). doi:10.1111/2041-210X.12139

81.R. Guimerà, L. A. N. Amaral, Functional cartography of complex metabolic networks. Nature 433, 895-900 (2005). doi:10.1038/nature03288

82.M. E. J. Newman, Analysis of weighted networks. Phys. Rev. E70, 056131 (2004). doi:10.1103/PhysRevE.70.056131

83.C. F. Dormann, B. Gruber, J. Fründ, Introducing the bipartite package: Analysing ecological networks. R News 8, 8-11 (2008).

84.P. Feinsinger, E. E. Spears, R. W. Poole, A simple measure of niche breadth. Ecology 62, 2732 (1981). doi:10.2307/1936664

85.J. Zhang, M. J. Zhang, Package 'spaa'. R package version 1. https://CRAN.Rproject.org/package=spaa (2013).

86.J. P. Huelsenbeck, R., Nielsen, J. P. Bollback, Stochastic mapping of morphological characters. Syst. Biol. 52, 131-158 (2003). doi:10.1080/10635150390192780

87.J. P. Bollback, SIMMAP: stochastic character mapping of discrete traits on phylogenies. $B M C$ Bioinformatics 7, 88 (2006). doi:10.1186/1471-2105-7-88

88.L. J. Harmon, J. T. Weir, C. D. Brock, R. E. Glor, W. Challenger, GEIGER: investigating evolutionary radiations. Bioinformatics 24, 129-131 (2008). doi:10.1093/bioinformatics/btm538 89.C. T. Stayton, Convevol: quantifies and assesses the significance of convergent evolution. $R$ package version 1.0. See http:// cran.r-project.org/ web/packages/convevol/index.html (2018). Phylogenetic ridge regression methods for comparative studies. Methods Ecol. Evol. 9, 974983 (2019). doi:10.1111/2041-210X.12954 

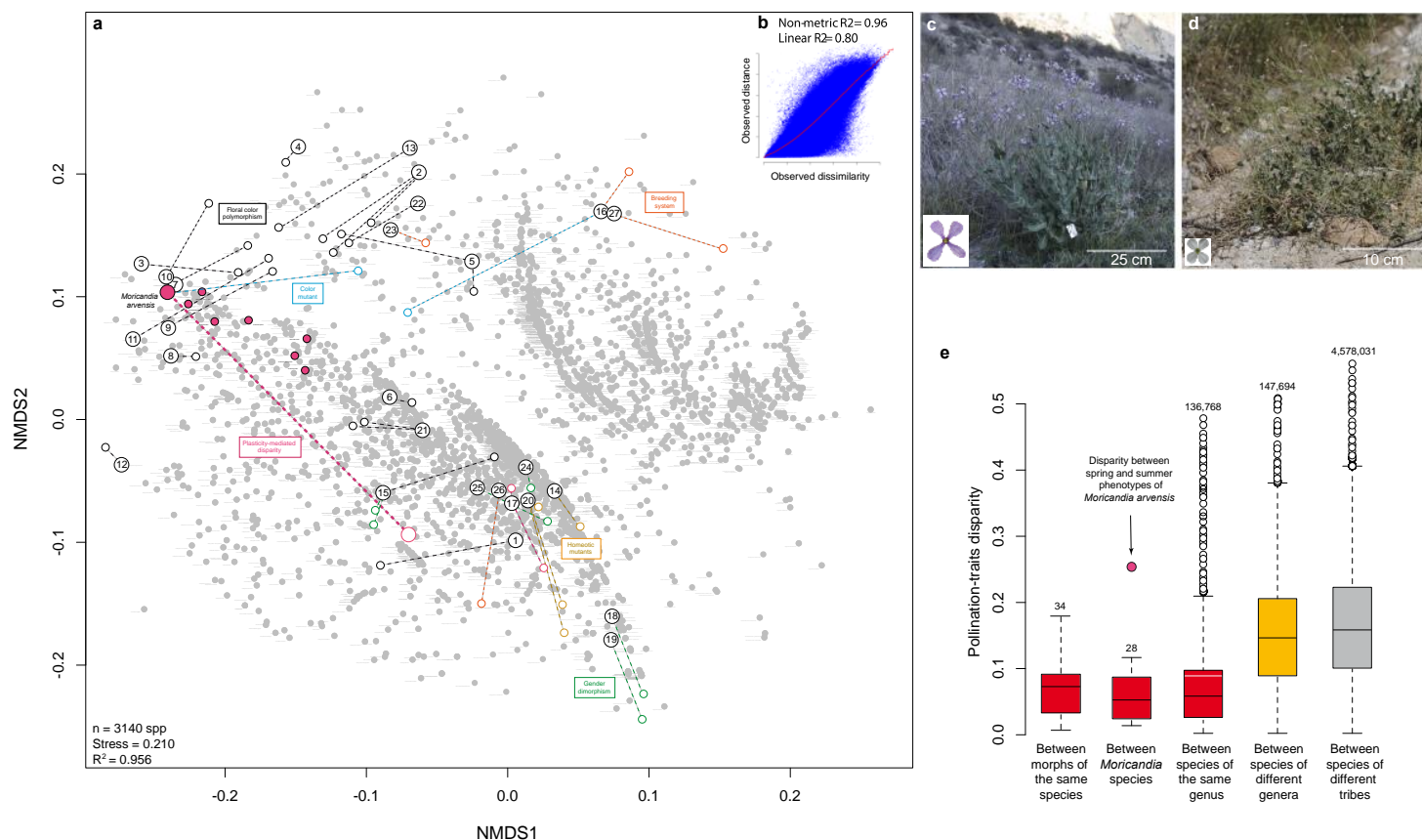

Figure 1. Plasticity-mediated floral disparity. (A) Floral morphospace of the Brassicaceae, showed as the projection of 31 traits recorded in 3140 species onto two NMDS axes. The position of the spring and summer phenotypes of Moricandia arvensis is linked by a thick lilac dashed line. We have also indicated the movements across this morphospace of several species changing their phenotypes due to floral colour polymorphism (black lines), single mutations in floral colour (blue lines), changes in breeding systems (orange lines), changes in gender expression (green lines), homeotic mutations (brown lines), and plasticity (lilac lines). Numbers matching species are as follow: 1-Lobularia maritima; 2-Raphanus raphanistrum; 3-Matthiola incana; 4-Mathiola fruticulosa; 5-Erysimum cheiri; 6-Cakile maritima; 7-Matthiola lunata; 8- Marcus-kochia littorea; 9-

793 Hesperis matronalis; 10- Hesperis laciniata; 11-Parrya nudicalis; 12-Streptanthus glandulosus;

794 13- Eruca vesicaria; 14- Capsella bursa-pastoris; 15-Hormathophylla spinosa; 16- Brassica

795 napus; 17-Cardamine hirsuta; 18-Lepidium sisymbrioides; 19-Lepidium solandri; 20-Arabidopsis

796 thaliana; 21-Boechera stricta; 22-Leavenworthia stylosa; 23-Leavenworthia crassa; 24-

797 Pachycladon stellatum; 25- Pachycladon walli; 26-Cardamine kokairensis; 27-Brassica rapa. (B)

798 Shepard plot showing the goodness of fit of the NMDS ordination. (C) Moricandia arvensis in 799 spring. (D) Moricandia arvensis in summer. (E) Magnitude of floral disparity between different 800 taxonomic levels of Brassicaceae species. The number above each boxplot shows the number of 801 disparities per level. We have compared this value with the disparity between spring and summer 
bioRxiv preprint doi: https://doi.org/10.1101/2021.05.25.445642; this version posted May 26, 2021. The copyright holder for this preprint (which

was not certified by peer review) is the author/funder, who has granted bioRxiv a license to display the preprint in perpetuity. It is made available under aCC-BY 4.0 International license.

802 phenotypes of $M$. arvensis (this comparison with boxplots in red is statistically significant at $P<$

8030.05 , in orange is marginally significant at $P<0.1$, and in grey is non-significant).

804

805 
a

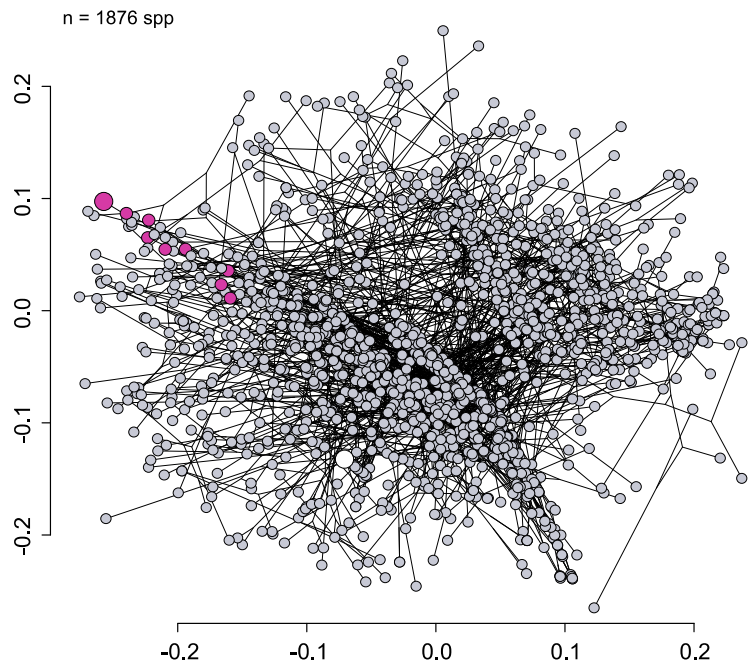

b $\quad n=8$ spp

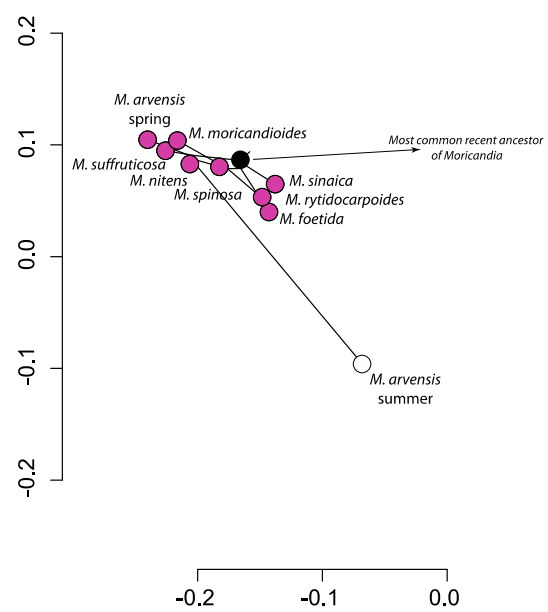
$\begin{array}{lllllllllllllllllll}8 & 255 & 248 & 163 & 48 & 124 & 208 & 109 & 26 & 265 & 77 & 126 & 23 & 28 & 89 & 55 & 53 & 94 & 117\end{array}$

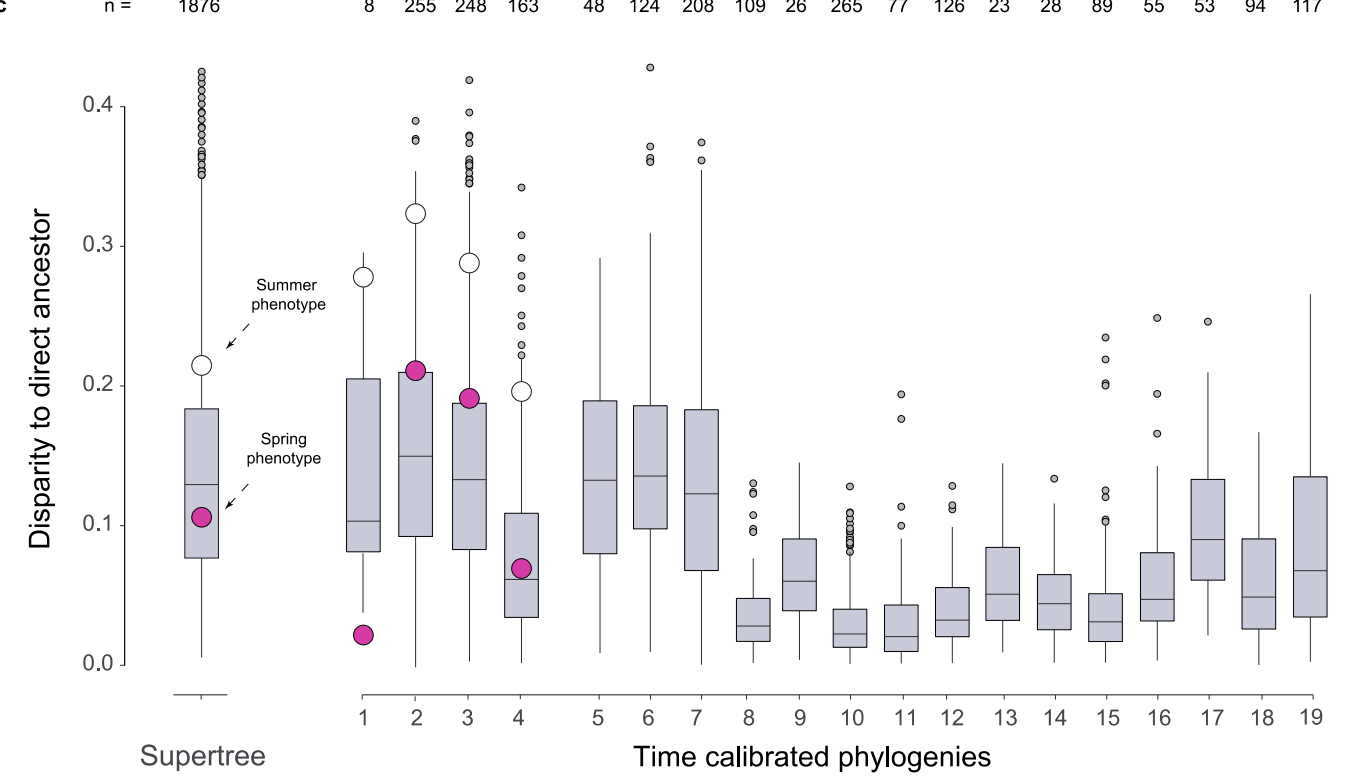

807

808 Figure 2. Phylogenetic-mediated floral divergence. (A) Floral phylomorphospace using the

809 supertree that includes 1876 Brassicaceae species. (B) Phylomorphospace considering only the 810 eight Moricandia species, using the Perfectti et al.'s phylogeny (phylogeny \# 1 in Table S8). (C)

811 Floral disparity to the nearest ancestor, according to the supertree and 18 time-calibrated

812 phylogenies (phylogeny codes in Table S8). We show the disparity between the two $M$. arvensis

813 phenotypes and their direct ancestor (spring: lilac dots; summer: white dots) in those phylogenies 
bioRxiv preprint doi: https://doi.org/10.1101/2021.05.25.445642; this version posted May 26, 2021. The copyright holder for this preprint (which

was not certified by peer review) is the author/funder, who has granted bioRxiv a license to display the preprint in perpetuity. It is made available under aCC-BY 4.0 International license.

814 that include Moricandia. We also show the disparities to their direct ancestors of those

815 Brassicaceae species included in time-calibrated phylogenies of more than 45 species.

816

817 
a

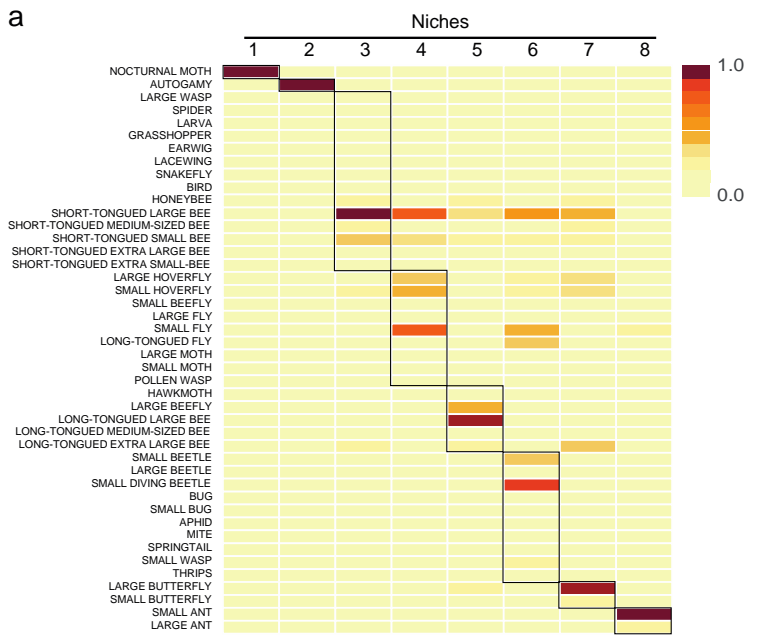

C

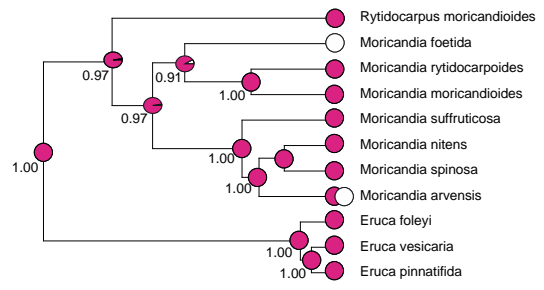

b

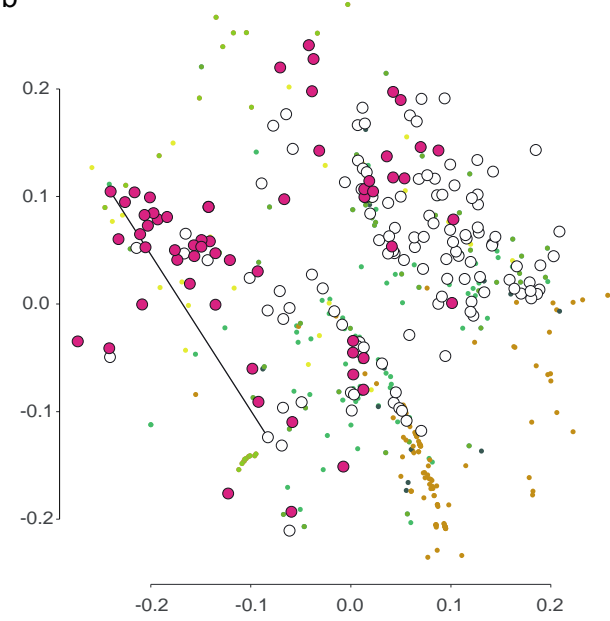

Niches Main pollinators

Niches Main pollinators

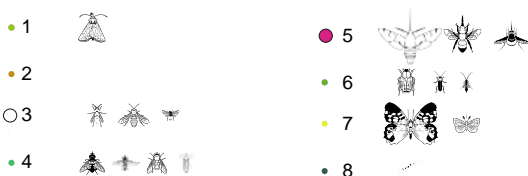

819

820

821

822

823

824

825

826

827

828

829

830
Figure 3. Plasticity-mediated changes in pollination niches. (A) Outcome of the modularity analysis showing the number of pollination niches inferred, the among-niche differences in relative frequency of each pollinator functional group, and the pollinator functional groups defining the niches ( $n=511$ Brassicaceae species). (B) Morphospatial distribution of the eight pollination niches detected in Brassicaceae. Insect silhouettes were drawn by Divulgare (www.divulgare.net) under a Creative Commons license (http://creativecommons.org/licenses/by-nc-sa/3.0). (C) Estimate of the ancestral pollination niche of the Moricandia lineage using a stochastic character mapping inference analysis. The numbers underneath each ancestral node indicate the posterior Bayesian probability of belonging to pollination niche 5 . 
Convergence inis polination niche 5

a

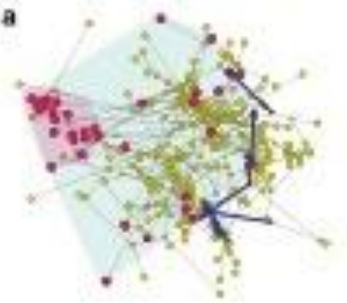

Convergenoe ints polination niche 3

d

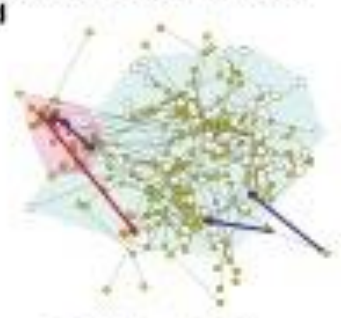

Smith a Browis shodogong

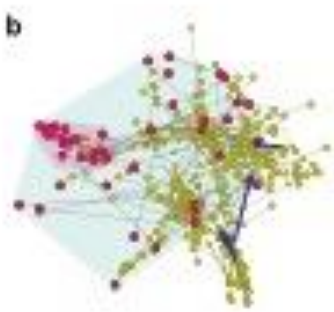

b

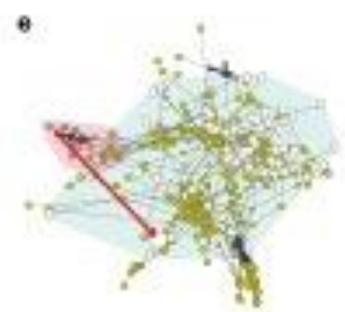

Gaynor ex als phylogeny

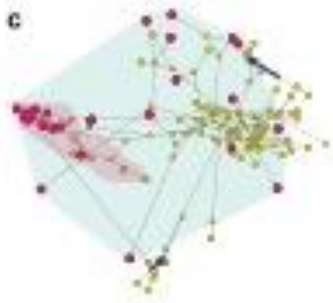

1

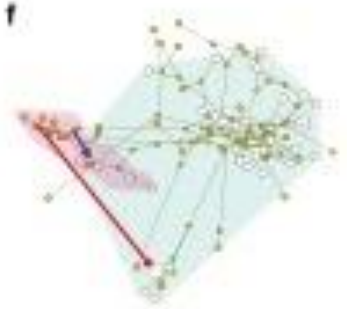

Huarg et alis phylogern.
831

832

833 Figure 4. Plasticity-mediated floral convergence. Convergent lineages crossing into the region

834 of the morphospace delimited by the pollination niche of the $M$. arvensis during spring (the shade

835

836

837

838

839

840

841

842

843

844 convex hull) according to (A) Smith \& Brown's phylogeny, (B) Gaynor et al.'s phylogeny, and (C) Huang et al.'s phylogeny (phylogenies 2-4, respectively, in Table S8). Convergent lineages crossing into the region of the morphospace delimited by the pollination niche of the $M$. arvensis during summer (the shade convex hull) according to (D) Smith \& Brown's phylogeny, (E) Gaynor et al.'s phylogeny, and (F) Huang et al.'s phylogeny. Red arrows indicate the plasticity-mediated convergence, blue arrows the convergence events of the other lineages. The small purple area in all panels is the region of the floral morphospace that includes the lineages that have converged with the entire Moricandia clade according to each time-calibrated phylogeny. 
bioRxiv preprint doi: https://doi.org/10.1101/2021.05.25.445642; this version posted May 26, 2021. The copyright holder for this preprint (which was not certified by peer review) is the author/funder, who has granted bioRxiv a license to display the preprint in perpetuity. It is made available under aCC-BY 4.0 International license.

\section{SI FIGURES}

Figure S1. Association among the 31 pollination traits of 3140 Brassicaceae species. Trait vectors represent the Spearman correlations, with the length and direction indicating the relationship with composite NMDS axes.

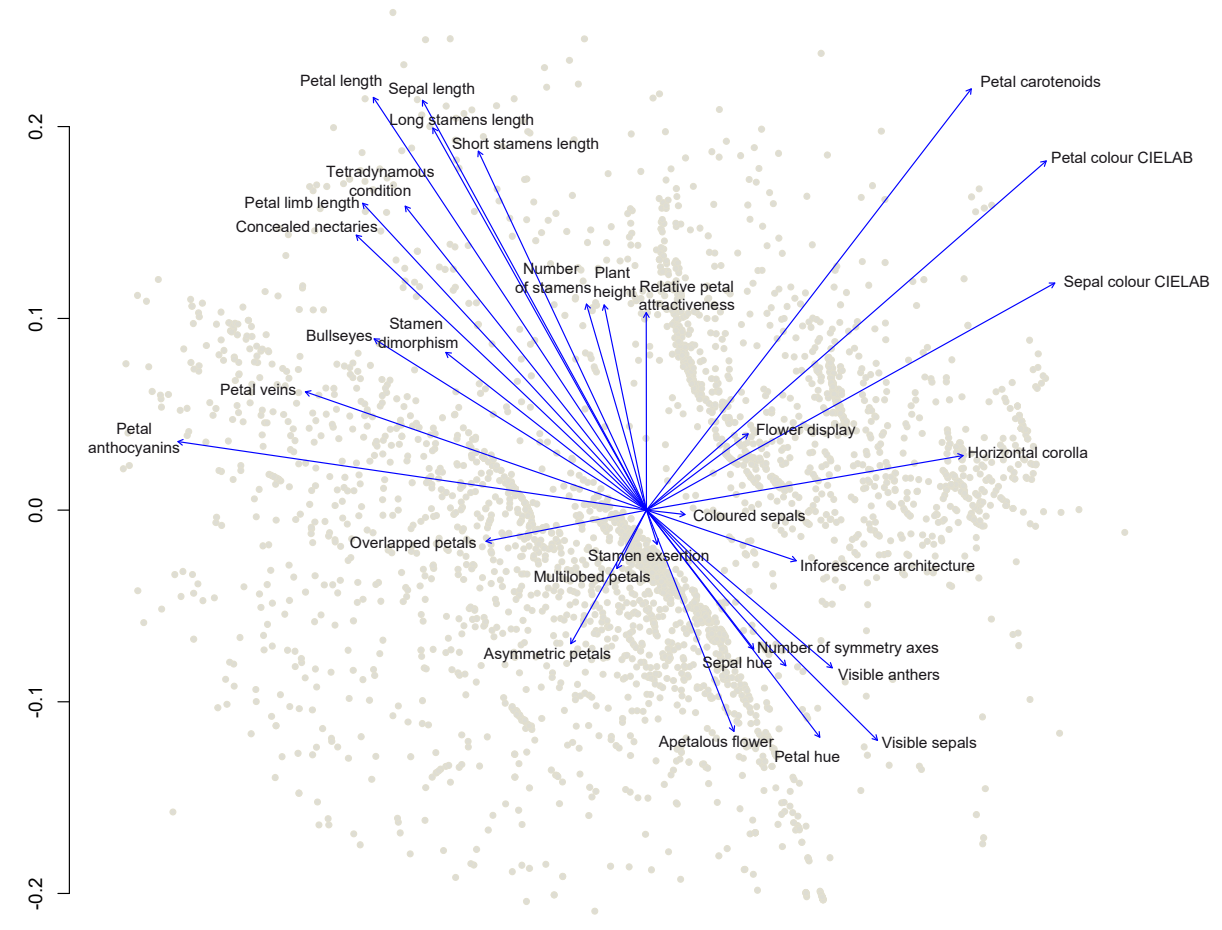

\begin{tabular}{ccccc}
\hline & & & & \\
-0.2 & -0.1 & 0.0 & 0.1 & 0.2
\end{tabular}




\section{SI TABLES}

Table S1. Fitting of the floral traits onto the NMDS vectors.

\begin{tabular}{|c|c|c|c|c|c|}
\hline & Floral traits & NMDS1 & NMDS2 & $r^{2}$ & P value \\
\hline 1 & Plant height & -0.20147 & 0.97949 & 0.1126 & 0.001 \\
\hline 2 & Flower display size & 0.80044 & 0.59942 & 0.0415 & 0.001 \\
\hline 3 & Inflorescence architecture & 0.94742 & -0.32001 & 0.0641 & 0.001 \\
\hline 4 & Presence of apetalous flowers & 0.36770 & -0.92994 & 0.1452 & 0.001 \\
\hline 5 & Number of symmetry axes of the corolla & 0.66735 & -0.74474 & 0.1121 & 0.001 \\
\hline 6 & Orientation of dominant symmetry axis of the corolla & 0.98547 & 0.16987 & 0.2650 & 0.001 \\
\hline 7 & Corolla with overlapped petals & -0.98142 & -0.19188 & 0.0685 & 0.001 \\
\hline 8 & Corolla with multilobed petals & -0.45075 & -0.89265 & 0.0110 & 0.001 \\
\hline 9 & Corolla with visible sepals & 0.70871 & -0.7055 & 0.2729 & 0.001 \\
\hline 10 & Petal length & -0.55200 & 0.83385 & 0.6287 & 0.001 \\
\hline 11 & Sepal length & -0.47963 & 0.87747 & 0.5594 & 0.001 \\
\hline 12 & Asymmetric petals & -0.49289 & -0.87009 & 0.0604 & 0.001 \\
\hline 13 & Petal limb length & -0.67904 & 0.73410 & 0.4482 & 0.001 \\
\hline 14 & Length of long stamen & -0.48773 & 0.87300 & 0.4915 & 0.001 \\
\hline 15 & Longeth of short stamen & -0.42415 & 0.90559 & 0.4029 & 0.001 \\
\hline 16 & Herkogamy & -0.78612 & 0.61808 & 0.1671 & 0.001 \\
\hline 17 & Herkogamy category & -0.62172 & 0.78324 & 0.3864 & 0.001 \\
\hline 18 & Visible anthers & 0.76256 & -0.64691 & 0.1526 & 0.001 \\
\hline 19 & Excerted stamens & 0.29511 & -0.95546 & 0.0033 & 0.009 \\
\hline 20 & Number of stamens & -0.28006 & 0.95998 & 0.1182 & 0.001 \\
\hline 21 & Concealed nectaries & -0.72601 & 0.68768 & 0.4101 & 0.001 \\
\hline 22 & Petal carotenoids & 0.61077 & 0.7918 & 0.7264 & 0.001 \\
\hline 23 & Petal anthocyanins & -0.98947 & 0.14476 & 0.5757 & 0.001 \\
\hline 24 & Presence of bulleyes & -0.84653 & 0.53235 & 0.2654 & 0.001 \\
\hline 25 & Presence of veins in the petals & -0.94487 & 0.32746 & 0.3343 & 0.001 \\
\hline 26 & Coloured sepal & 0.99357 & -0.11318 & 0.0039 & 0.002 \\
\hline 27 & Relative attractiveness of petals versus sepals & -0.00049 & 0.99990 & 0.1001 & 0.001 \\
\hline 28 & Petal hue & 0.60720 & -0.79455 & 0.2096 & 0.001 \\
\hline 29 & Petal colour as b CIELAB & 0.75326 & 0.65772 & 0.7232 & 0.001 \\
\hline 30 & Sepal Hue & 0.61109 & -0.79156 & 0.0791 & 0.001 \\
\hline 31 & Sepal colour as b CIELAB & 0.87412 & 0.48571 & 0.5605 & 0.001 \\
\hline
\end{tabular}


bioRxiv preprint doi: https://doi.org/10.1101/2021.05.25.445642; this version posted May 26, 2021. The copyright holder for this preprint (which was not certified by peer review) is the author/funder, who has granted bioRxiv a license to display the preprint in perpetuity. It is made available under aCC-BY 4.0 International license.

Table S2. Disparity, calculated as the Euclidean distance in the family-wide floral morphospace, between each of the 38 morphs included in our dataset (see Supplementary Data 2 for details and references) and their respective wild types.

\begin{tabular}{|c|c|c|c|}
\hline Type of polymorphism & Species & Morph & NMDS \\
\hline Breeding system & Brassica napus & cleistogamous mutant & 0.035856865 \\
\hline Breeding system & Brassica rapa & female sterility mutant & 0.133332180 \\
\hline Breeding system & Cardamine kokairensis & cleistogamous mutant & 0.111696867 \\
\hline Breeding system & Leavenworthia crassa & Outcrosser morph & 0.015771684 \\
\hline Colour mutant & Brassica napus & white mutant & 0.173001555 \\
\hline Colour mutant & Moricandia arvensis & white mutant & 0.149565069 \\
\hline Flower colour polymorphism & Boechera stricta & pink morph & 0.060580070 \\
\hline Flower colour polymorphism & Boechera stricta & purple morph & 0.054429426 \\
\hline Flower colour polymorphism & Cakile maritima & white morph & 0.016547552 \\
\hline Flower colour polymorphism & Eruca vesicaria & white morph & 0.082257145 \\
\hline Flower colour polymorphism & Erysimum cheiri & purple cultivar & 0.073997237 \\
\hline Flower colour polymorphism & Erysimum cheiri & white cultivar & 0.026460490 \\
\hline Flower colour polymorphism & Hesperis laciniata & white morph & 0.069557518 \\
\hline Flower colour polymorphism & Hesperis matronalis & white morph & 0.094873544 \\
\hline Flower colour polymorphism & Hormathophylla spinosa & white morph & 0.101607789 \\
\hline Flower colour polymorphism & Leavenworthia stylosa & white morph & 0.066269050 \\
\hline Flower colour polymorphism & Lobularia maritima & deep purple cultivar & 0.090407642 \\
\hline Flower colour polymorphism & Marcus-kochia littorea & light pink morph & 0.019542946 \\
\hline Flower colour polymorphism & Matthiola fruticulosa & greenish morph & 0.008349920 \\
\hline Flower colour polymorphism & Matthiola incana & white cultivar & 0.138357728 \\
\hline Flower colour polymorphism & Matthiola lunata & white morph & 0.079964493 \\
\hline Flower colour polymorphism & Parrya nudicaulis & white morph & 0.115226060 \\
\hline Flower colour polymorphism & Raphanus raphanistrum & white morph & 0.082072459 \\
\hline Flower colour polymorphism & Raphanus raphanistrum & yellow morph & 0.032685632 \\
\hline Flower colour polymorphism & Raphanus raphanistrum & pink morph & 0.082778860 \\
\hline Flower colour polymorphism & Streptanthus glandulosus & white morph & 0.014907493 \\
\hline Gender dimorphism & Hormathophylla spinosa & female morph & 0.035783402 \\
\hline Gender dimorphism & Hormathophylla spinosa & male morph & 0.025226337 \\
\hline Gender dimorphism & Lepidium sisymbrioides & female morph & 0.067913758 \\
\hline Gender dimorphism & Lepidium solandri & female morph & 0.065685257 \\
\hline Gender dimorphism & Pachycladon stellatum & female morph & 0.014244744 \\
\hline Gender dimorphism & Pachycladon wallii & male morph & 0.059320935 \\
\hline Homeotic mutant & Arabidopsis thaliana & AGAMOUS mutant & 0.001052532 \\
\hline Homeotic mutant & Arabidopsis thaliana & APETALA1 mutant & 0.119617731 \\
\hline Homeotic mutant & Arabidopsis thaliana & APETALA3 mutant & 0.102445400 \\
\hline Homeotic mutant & Capsella bursapastoris & Spe mutant & 0.051187659 \\
\hline Phenotypic plasticity & Cardamine hirsuta & plastic change in stamens number & 0.010624208 \\
\hline Phenotypic plasticity & Cardamine hirsuta & plastic change in petal number & 0.060755859 \\
\hline
\end{tabular}


bioRxiv preprint doi: https://doi.org/10.1101/2021.05.25.445642; this version posted May 26, 2021. The copyright holder for this preprint (which was not certified by peer review) is the author/funder, who has granted bioRxiv a license to display the preprint in perpetuity. It is made available under aCC-BY 4.0 International license.

Table S3. Floral disparity of each species of Moricandia from the most recent common ancestor (MRCA) of the genus and from the direct ancestor of each species.

\begin{tabular}{lcc}
\hline Species & Disparity to MRCA & $\begin{array}{c}\text { Disparity to direct } \\
\text { ancestor }\end{array}$ \\
\hline Moricandia foetida & 0.039566021 & 0.13987379 \\
Moricandia moricandioides & 0.059142993 & 0.03730920 \\
Moricandia nitens & 0.041727403 & 0.07347209 \\
Moricandia rytidocarpoides & 0.025809374 & 0.10503623 \\
Moricandia sinaica & 0.027589330 & 0.10550411 \\
Moricandia spinosa & 0.019579372 & 0.20959717 \\
Moricandia suffruticosa & 0.063884437 & 0.20700167 \\
Moricandia arvensis spring phenotype & 0.080840848 & 0.02385532 \\
Moricandia arvensis summer phenotype & 0.195061288 & 0.28741584 \\
\hline
\end{tabular}


Table S4. Significance of the Mantel tests checking for spatial autocorrelation across the morphospace of the pollinator functional groups. Due to the small abundance of some pollinators, the original 43 functional groups have been pooled in 26 main functional groups.

\begin{tabular}{lcc}
\hline Functional Groups & Mantel R & p value \\
\hline Ant & 0.047 & 0.055 \\
Autogamy & 0.257 & 0.001 \\
Bug & 0.032 & 0.192 \\
Butterfly & 0.089 & 0.001 \\
Hawkmoth & 0.054 & 0.035 \\
Hoverfly & 0.072 & 0.003 \\
Large beefly & 0.043 & 0.079 \\
Large beetle & 0.046 & 0.063 \\
Large fly & 0.052 & 0.044 \\
Large wasp & 0.053 & 0.048 \\
Long tongued fly & 0.092 & 0.001 \\
Long tongued large bee & 0.242 & 0.001 \\
Long tongued medium-sized bee & 0.051 & 0.041 \\
Moth & 0.039 & 0.113 \\
Nocturnal moth & 0.222 & 0.001 \\
Other & 0.018 & 0.497 \\
Pollen wasp & 0.026 & 0.313 \\
Small beetle & 0.012 & 0.613 \\
Small diving beetle & 0.003 & 0.899 \\
Small fly & 0.112 & 0.001 \\
Small wasp & 0.041 & 0.112 \\
Short tongued large bee & 0.065 & 0.004 \\
Short tongued medium-sized bee & 0.012 & 0.590 \\
Short tongued small bee & 0.073 & 0.001 \\
Short tongued extra small bee & 0.020 & 0.454 \\
Thrips & -0.014 & 0.758 \\
\hline
\end{tabular}


Table S5. Diferences between the two Moricandia arvensis phenotypes in the visitation frequency (both in absolute number of insects and in proportion of visits) of every pollinator functional group. Fifteen censuses of $1 \mathrm{hr}$ and two researchers per phenotype.

\begin{tabular}{|c|c|c|c|c|}
\hline Pollinator functional group & $\begin{array}{c}\text { spring } \\
\text { phenotype }\end{array}$ & $\begin{array}{c}\text { summer } \\
\text { phenotype }\end{array}$ & $\begin{array}{c}\text { spring } \\
\text { phenotype } \\
\text { (proportion) }\end{array}$ & $\begin{array}{c}\text { summer } \\
\text { phenotype } \\
\text { (proportion) }\end{array}$ \\
\hline Hawkmoth & 91 & 0 & 0.036 & 0.000 \\
\hline Honeybee & 40 & 0 & 0.016 & 0.000 \\
\hline Large beefly & 309 & 72 & 0.124 & 0.148 \\
\hline Large beetle & 30 & 40 & 0.012 & 0.082 \\
\hline Large butterfly & 280 & 66 & 0.112 & 0.135 \\
\hline Large fly & 38 & 0 & 0.015 & 0.000 \\
\hline Large hoverfly & 8 & 7 & 0.003 & 0.014 \\
\hline Long tongued large bee & 1131 & 5 & 0.453 & 0.010 \\
\hline Long tongued medium-sized bee & 226 & 0 & 0.090 & 0.000 \\
\hline Small beefly & 6 & 0 & 0.002 & 0.000 \\
\hline Small beetle & 21 & 8 & 0.008 & 0.016 \\
\hline Small butterfly & 11 & 0 & 0.004 & 0.000 \\
\hline Small diving beetle & 25 & 12 & 0.010 & 0.025 \\
\hline Small fly & 12 & 0 & 0.005 & 0.000 \\
\hline Small hoverfly & 49 & 37 & 0.020 & 0.076 \\
\hline Small moth & 2 & 7 & 0.001 & 0.014 \\
\hline Short tongued large bee & 89 & 3 & 0.036 & 0.006 \\
\hline Short tongued medium-sized bee & 36 & 0 & 0.014 & 0.000 \\
\hline Short tongued small bee & 78 & 207 & 0.031 & 0.424 \\
\hline Short tongued extra small bee & 1 & 0 & 0.000 & 0.000 \\
\hline Thrips & 15 & 24 & 0.006 & 0.049 \\
\hline
\end{tabular}


Table S6. Outcome of the analyses to test the occurrence of floral convergence among plants from niches 3 and 5 . Angle is the mean theta angle between all species belonging to the same niche. Angle/time is the angle divided by time distance. The significance of these angles has been found by comparing with a null model consisting in shuffling each niche 1,000 times across the tree tips and calculating a distribution of random angle. $\mathbf{C 1}$ measures the proportion of phenotypic distance closed by evolution, ranging from 0 to 1 (where 1 indicates complete convergence). $\mathbf{C 2}$ is the raw value of the difference between the maximum and extant distance between the lineages. C3 is $\mathrm{C} 2$ scaled by the total evolution (sum of squared ancestor-to-descendant changes) between the two lineages. $\mathbf{C} 4$ is $\mathrm{C} 2$ scaled by the total evolution in the whole clade. The significance of $\mathrm{C} 1-\mathrm{C} 2$, was evaluated by running 1000 simulations for each comparison using Brownian-Motion models. Wheatleaf is the ratio of the mean (penalized) distances between all species to the mean (penalized) distances between allegedly convergent species. Significance found by running 2000 bootstrapping simulations. In bold, significant values.

\begin{tabular}{|c|c|c|c|c|c|c|}
\hline \multirow{2}{*}{ Phylogenies } & \multicolumn{2}{|c|}{ Smith \& Brown 2018} & \multicolumn{2}{|c|}{ Gaynor et al. 2018} & \multicolumn{2}{|c|}{ Huang et al. 2019} \\
\hline & Value & $\mathrm{p}$ & Value & $p$ & Value & $p$ \\
\hline \multicolumn{7}{|l|}{ Niche 3} \\
\hline Angle & 80.587 & 0.008 & 79.431 & 0.002 & 64.930 & 0.055 \\
\hline Angle/time & 2.350 & 0.719 & 1.645 & 0.397 & 4.023 & 0.815 \\
\hline C1 & 0.373 & 0.000 & 0.472 & 0.000 & 0.415 & 0.000 \\
\hline C2 & 0.104 & 0.000 & 0.142 & 0.000 & 0.104 & 0.000 \\
\hline C3 & 0.141 & 0.000 & 0.166 & 0.000 & 0.219 & 0.000 \\
\hline C4 & 0.003 & 0.720 & 0.002 & 0.700 & 0.008 & 0.600 \\
\hline Wheatleaf & 0.830 & 0.986 & 0.940 & 0.715 & 1.060 & 0.028 \\
\hline \multicolumn{7}{|l|}{ Niche 5} \\
\hline Angle & 70.093 & 0.002 & 73.491 & 0.002 & 58.313 & 0.049 \\
\hline Angle/time & 1.393 & 0.021 & 1.783 & 0.745 & 2.474 & 0.011 \\
\hline $\mathrm{C} 1$ & 0.356 & 0.000 & 0.472 & 0.000 & 0.240 & 0.000 \\
\hline $\mathrm{C} 2$ & 0.110 & 0.000 & 0.142 & 0.000 & 0.075 & 0.000 \\
\hline C3 & 0.128 & 0.000 & 0.166 & 0.000 & 0.118 & 0.000 \\
\hline C4 & 0.003 & 0.727 & 0.002 & 0.700 & 0.006 & 0.545 \\
\hline Wheatleaf & 1.120 & 0.673 & 1.170 & 0.094 & 0.920 & 0.978 \\
\hline
\end{tabular}


Table S7. Outcome of the analyses testing for morphological convergence between the Moricandia clade and the rest of clades included in each time-calibrated phylogeny. Clade size is the number of species within the Moricandia clade. $\boldsymbol{\theta}_{\text {real }}$ is the mean angle over all possible combinations of pairs of species taking one species per

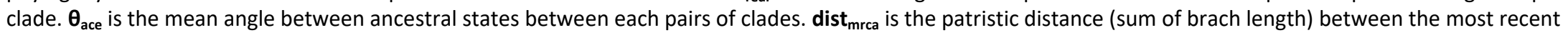
common ancestors of each pair of clade. We indicate the congervent clades and the pollination niches of each species included in the convergent clades. In red Moricandia

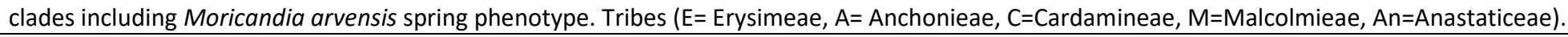

\begin{tabular}{|c|c|c|c|c|c|c|c|c|c|c|c|c|}
\hline $\begin{array}{c}\text { Moricandia } \\
\text { clade }\end{array}$ & $\begin{array}{c}\text { Clade } \\
2\end{array}$ & $\begin{array}{l}\text { Clade } \\
\text { size }\end{array}$ & $\theta_{\text {real }}$ & $\theta_{\text {ace }}$ & dist $_{\text {mrca }}$ & $\begin{array}{c}\theta_{\text {real }} / \\
\text { dist }_{\text {mrca }}\end{array}$ & $\begin{array}{c}\theta_{\text {real }} / \text { dist }_{\text {mrca }} \\
\text { p-value }\end{array}$ & $\begin{array}{c}\theta_{\text {ace }}+\theta_{\text {real }} / \\
\text { dist }_{\text {mrca }}\end{array}$ & $\begin{array}{c}\theta_{\text {ace }}+\theta_{\text {real }} / \\
\text { dist }_{\text {mrca }} \\
\text { p-value }\end{array}$ & Convergent clades & Tribe & Niche \\
\hline \multicolumn{13}{|c|}{ Smith \& Brown's phylogeny } \\
\hline 254 & 347 & 5 & 19.035 & 5.389 & 129.718 & 0.147 & 0.058 & 0.188 & 0.016 & Erysimum bicolor/ scoparium & $\mathrm{E}$ & 5,5 \\
\hline 255 & 347 & 4 & 22.601 & 6.331 & 133.342 & 0.169 & 0.052 & 0.217 & 0.019 & Erysimum bicolor/ scoparium & $\mathrm{E}$ & 5,5 \\
\hline 256 & 347 & 2 & 6.180 & 7.281 & 133.538 & 0.046 & 0.026 & 0.101 & 0.005 & Erysimum bicolor/ scoparium & $\mathrm{E}$ & 5,5 \\
\hline 256 & 316 & 2 & 12.950 & 2.109 & 59.810 & 0.217 & 0.061 & 0.252 & 0.018 & Matthiola clade & A & 6,1 \\
\hline 256 & 375 & 2 & 8.543 & 13.786 & 49.285 & 0.173 & 0.066 & 0.453 & 0.045 & Cardamine penthaphyllo/ pratensis & $\mathrm{C}$ & 3,7 \\
\hline 256 & 405 & 2 & 8.616 & 1.048 & 44.577 & 0.193 & 0.068 & 0.217 & 0.022 & Malcolmia maritima - Marcus-kochia ramosissima & M/An & 5,7 \\
\hline 256 & 335 & 2 & 28.715 & 33.529 & 128.518 & 0.223 & 0.077 & 0.484 & 0.049 & Erysimum popovii/ bastetanum/ semperflorens & $\mathrm{E}$ & $5,5,6$ \\
\hline 257 & 347 & 2 & 39.021 & 6.003 & 133.462 & 0.292 & 0.103 & 0.337 & 0.015 & Erysimum bicolor/ scoparium & $\mathrm{E}$ & 5,5 \\
\hline 258 & 347 & 2 & 5.613 & 4.410 & 124.383 & 0.045 & 0.012 & 0.081 & 0.002 & Erysimum bicolor/ scoparium & $\mathrm{E}$ & 5,5 \\
\hline \multicolumn{13}{|c|}{ Gaynor et al.'s phylogeny } \\
\hline 479 & 334 & 2 & 9.357 & 12.654 & 81.141 & 0.115 & 0.052 & 0.271 & 0.033 & Erysimum bicolor/ scoparium & $\mathrm{E}$ & 5,5 \\
\hline 479 & 333 & 2 & 12.809 & 14.978 & 81.151 & 0.158 & 0.070 & 0.342 & 0.049 & Erysimum lagascae/ rondae & $\mathrm{E}$ & 5,3 \\
\hline \multicolumn{13}{|c|}{ Huang et al.'s phylogeny } \\
\hline 143 & 83 & 2 & 4.960 & 0.985 & 23.966 & 0.207 & 0.023 & 0.248 & 0.001 & Erucaria clade & B & 3,5 \\
\hline 143 & 82 & 2 & 7.094 & 0.554 & 22.049 & 0.322 & 0.041 & 0.347 & 0.002 & Erucaria clade + Cakile clade & B & $3,3,3,5$ \\
\hline 143 & 81 & 2 & 6.651 & 40.317 & 18.008 & 0.369 & 0.046 & 2.608 & 0.170 & Erucaria clade + Cakile clade + Eremophyton chevallieri & B & $3,3,3,5,5$ \\
\hline 143 & 84 & 2 & 9.229 & 1.876 & 23.466 & 0.393 & 0.066 & 0.473 & 0.003 & Cakile clade & B & 3,3 \\
\hline 143 & 86 & 2 & 11.634 & 12.691 & 24.281 & 0.479 & 0.074 & 1.002 & 0.026 & Zilla clade & B & 5,5 \\
\hline 143 & 85 & 2 & 9.383 & 12.437 & 24.007 & 0.391 & 0.076 & 0.909 & 0.029 & Zilla clade + Foleyola billotii & B & $3,5,5$ \\
\hline
\end{tabular}


Table S8. Description of floral traits related to pollinator attraction used to generate the floral morphospace in Brassicaceae. Pollinators respond to the variability of numerous phenotypic traits of plants, and the magnitude of their response shapes the reproductive success of the plants. We estimated for each plant included in our data set the values of several important floral traits.

1) Plant height. Plant height has strong direct and indirect effects on plant fitness in many Brassicaceae. The assessment of plant height for a large number of plant species is not possible without accurate ecological studies. In addition, the information on plant size in general (and plant height in particular) appearing in the floristic catalogues is limited and most time very vague. For this reason, we decided to consider this variable as semiquantitative, with three levels:

$0=$ This group includes plants with a prostrate life habit. Plants belonging to this group are those with a cushion shape, displaying flowers located very close to the ground and that thereby can be accessed both by flying and crawling insects (ants, springtails, mites, etc.).

1 = This group includes plants of intermediate size. We included in this group those plants shorter than $50 \mathrm{~cm}$. This threshold is appropriate because it teases apart medium-sized species from those species with a large size. Many pollinators have a specific flight pattern with changes in flight zones occurring around this threshold. Within this group, there are also subshrub species with stunted growth habit.

$2=$ This group includes plants of large size. We included in this group those plants taller than $50 \mathrm{~cm}$. These are plants particularly big, usually log-lived and sometimes woody species.

(2) Flower display size. The number of flowers produced per individual plant has strong direct and indirect effects on plant fitness in most Brassicaceae species. As occurring with plant height, the assessment of floral display size for a large number of plant species is not possible without accurate ecological studies. In addition, the information on flower number per individual appearing in the floristic catalogues is limited and most time very vague. For this reason, we decided to consider this variable as semi-quantitative, with three levels:

$0=$ This group includes species with few flowers per individual (pauciflorous), usually less than 50 flowers per individual.

$1=$ This group includes species with medium number to many flowers per individuals, usually between 50 and 1000 flowers per individual.

$2=$ This group includes species mass-flowering species, usually with more than 1000 flowers per individual.

(3) Inflorescence architecture. The configuration of flowers along the flowering stems and the inflorescence architecture have been shown to affect the attractiveness and foraging behaviour of pollinators in many angiosperm groups since long time. In Brassicaceae three main types of inflorescences can be distinguished:

$0=$ Inflorescences where flowers are arranged in solitary. In this species, flowers do not form a dense inflorescence but are solitary usually at the end of the flowering stems. 
$1=$ Inflorescences where flowers are arranged in racemes. A simple inflorescence in which the main axis is indeterminate. This is the most frequent type of inflorescence in Brassicaceae.

$2=$ Inflorescences where flowers are arranged in corymbs. This is a special case of a panicle where flowers lie in a single plane. Panicles are determinate compound inflorescences in which branching does not occur from the axils of prophylls.

(4) Presence of apetalous flowers. Several species from some Brassicaceae genera, especially Lepidium and Rorippa, and to a lesser extent Romanschulzia, Clypeola, Cardamine and other minor genera, produce flowers without petals. We classified this floral trait as presence (1) or absence (0) of apetalous flowers.

(5) Number of symmetry axes of the corolla. Flower symmetry is an important trait in flowering plants. The Brassicaceae flower is defined as a cruciform, actinomorphic or radial flowers with many symmetry axes. However, it is widely acknowledged that some genera such as Iberis or Teesdalia produce monomorphic or actinomorphic flowers. The number of symmetry axes is even greater in some species. We have distinguished four groups based on number of symmetry axes:

$0=$ This group includes plants with flowers having no symmetry axis, like many species of Matthiola, some Hesperis,

1 = This group includes plants bearing flowers with one symmetry axis or actinomorphic flowers. In this group we included Iberis, Teesdalia, and several species of Noccaea, Thlaspi, etc.

$2=$ This group includes plants bearing flowers with two symmetry axes or dissymmetric flowers. This is probably the most abundant group, including most common species of Brassicaceae, like Erysimum, Brassica, Diplotaxis, etc.

$4=$ This group includes plants bearing flowers with four or more symmetry axes or polysymmetric flowers. This group, including common species of Brassicaceae, like Lepidium, some Erysimum, many Heliophila, many Sisymbrium, etc.

(6) Orientation of dominant symmetry axis of the corolla. In Brassicaceae, most flowers orientate vertically. Thereby, we classified this floral trait as horizontally- (1) or vertically- (0) orientated flowers.

(7) Corolla with overlapped petals. Much like flower symmetry, the presence of overlapped petals and rounded corollas affect fitness in several plant groups, including some Brassicaceae species by mediating the attractiveness of the flowers and the behaviour of pollinators. We classified this floral trait as corolla with overlapped petals (1) or with non-overlapped petals (0).

(8) Corolla with multilobed petals. In Brassicaceae petal lobes is not widespread, although it is frequent in some clades such as Schizopetalon, Berteroa, Dryopetalon. We classified this floral trait as corolla with multilobed petals (1) or without them (0).

(9) Corolla with visible sepals. Sepals play an important role in the pollination of many plant species. Some plant species, including Brassicaceae, have extended sepals that are visible from the top of the corolla. These visible petals may have important consequences on the behaviour of some pollinators, indirectly influencing the pollination success of the 
flower. We scored this floral trait as corolla with visible sepals from the top of the corolla (1) or not (0).

(10) Petal length. Different studies have found a significant association between the length of flower petals and the behaviour of pollinators, by increasing corolla size and attractiveness or the floral attraction surface. As a consequence, it has been frequently proven the occurrence of a significant effect of petal length and flower size on the efficiency of pollination. We included in the data set the length of the petal in $\mathrm{mm}$ of each plant species. For this, we retrieved from the literature the description of the petal length, and calculated the mean of the values appearing in that description.

(11) Sepal length. In Brassicaceae the length of the sepals is positively correlated with the length of the corolla tube and the amount of nectar produced by the flowers. We included in the data set the length of the sepals in mm of each plant species. As in traits 10, we retrieved from the literature the description of the sepal length, and calculated the mean of the values appearing in that description.

(12) Asymmetric petals. Brassicaceae is characterized for bearing four symmetric petals. However, some species exhibit corollas with asymmetric petals, a character considered a morphological novelty. Presence of asymmetric petals causes corollas to show zygomorphy. This character, by affecting in an extreme way the number of symmetry axes, have larges effects on pollinator preference, pollination efficiency and reproduction success. We scored this floral trait as corolla with asymmetric petals (1) or not (0).

(13) Petal limb length. The limb of the petal is the showy part that directly attracts pollinators. We included in the data set the length of the petal limb in mm of each plant species. For this, we retrieved from the literature the description of the petal length, and calculated the mean of the values appearing in that description.

(14) Length of long stamens. Brassicaceae has a tetradynamous androceum, with an outer whorl of two short stamens and an inner whorl of four long stamens. The length of the long stamens has been proven to affect pollinator visitation rate and effectiveness, having a strong effect on pollen removal and male fitness. We included in the data set the length of the long stamen in mm of each plant species as appearing in the literature.

(15) Length of short stamens. Short stamens may function in outcrossing Brassicaceae to reduce pollen depletion with high rates of pollinator visitation. In self-compatible, short stamens may favour delayed autogamy. In addition, short stamens may also affect pollinator visitation rate and effectiveness, having potential effect on pollen removal and male. We included in the data set the length of the short stamen in mm of each plant species as appearing in the literature.

(16) Stamen dimorphism. The difference in length between long and short stamens, hereinafter herkogamy, is related in Brassicaceae with pollinator attraction and evolution of selfing syndrome. We included this trait by estimating the length difference between long and short stamens from the data obtained in the literature.

(17) Tetradynamous conditions. In addition, we classified all Brassicaceae included in our dataset as having an androecium with all stamens equally long (0), slightly tetradynamous (1), normal tetradynamous condition (2) and strong tetradynamous condition (3). We used the classification appearing in the floral and formal description of the species. 
(18) Visible anthers. Most species of Brassicaceae have anthers visible from outside the corolla during anthesis, which ease the magnitude of pollen removal by flower visitors. However, species of some genera (Matthiola, Hesperis, Farsetia, etc.) have stamens well hidden within the corolla tube and imperceptible from outside, a trait that difficult shorttongued insects to collect pollen. We scored this floral trait as corolla with visible anthers (1) or not (0).

(19) Exserted stamens. In some Brassicaceae the filaments are very long, causing stamens to be highly exserted. Stamens exsertion influences the behaviour and abundance of certain pollinators, shaping pollinator-mediated selection through male fitness. We scored this floral trait as non-exserted stamens (0) slightly exserted stamens (1) and strongly exserted stamens (2).

(20) Number of stamens. The basic number of stamens per Brassicaceae flower is six. However, departure from this number is frequent in some lineages such as Lepidium or to a lesser extent Cardamine or Alyssum, where some species bear 2, 4 or 5 stamens. In addition, some species of the genus Megacarpea have flowers with 9 or more stamens. We included for each species in the dataset the number of stamens indicated in the literature.

(21) Concealed nectaries. Some Brassicaceae species produce nectar that is concealed in the bottom of long corolla tubes, whereas other species bearing bowl-shaped flowers produce nectar that is freely exposed an easily accessible. This trait may have important consequences for the interaction with pollinators. We scored this floral trait as corolla with concealed nectaries (1) or not (0).

(22) Petal carotenoids. Flower colour is a crucial visual cue used by pollinators to locate flowers. In the Brassicaceae, there are numerous studies highlighting the role of flower colour in pollinator attraction and plant reproduction. Petal colour is mainly determined by the presence of pigments; we thereby decided to include the presence or absence of floral pigments in our dataset. Yellow colour is produced in Brassicaceae by the accumulation of carotenoids. We scored this trait as the presence (1) or absence (0) of petal carotenoids.

(23) Petal anthocyanins. In the Brassicaceae, species with pink, lilac, blue, purple, orange and red petals are caused by the accumulation of anthocyanins. We scored this floral trait as the presence of petal anthocyanins (1) or absence (0).

(24) Presence of bullseyes. Some flowers have circular patterns in the centre of the corolla called bullseyes that is involved in the attraction of pollinators. Bullseyes may be visible to human vision or invisible due to its absorbance in the ultraviolet region of the light spectrum; we considered only the first ones as is the information provide in the consulted Floras. We scored this floral trait as corolla with (1) or without (0) bullseyes.

(25) Presence of veins in the petals. In the Brassicaceae, some species may show petals with prominent veins having a different colour from the rest of the petals. The presence of coloured veins in the petals may function as nectar guides, providing visual orientation directing the pollinator to the central landing platform and the entrance to the flower. We scored this floral trait as petals with (1) or without (0) veins.

(26) Coloured sepals. As commented in the trait 9, sepals may be involved in pollination attraction in many species. Colouring sepals by accumulating anthocyanins or carotenoids and may help flowers to differentiate from the green background. We scored this floral trait as coloured sepals (1) or green sepals (0). 
(27) Relative attractiveness of petals versus sepals. In some species of the Brassicaceae, the sepals are bigger and more attractive than the petals. This occurs frequently in some genera such as Streptanthus, Roripa, Lepidium and Heliophila. We scored this floral trait as (1) when petals are more attractive than sepals or (0) in the opposite case.

(28) Petal hue. Although measuring flower colour with spectrophotometric methods are recommended over methodologies based on human vision, obtaining reflectance data of more than 3000 species widely distributed around the world is virtually unfeasible. We designed a method that allows incorporating colour description in the Floras to generate categorical variables. We used a modification of colour identification with reference standards which are commonly used in comparative studies of flower colour and generates relatively good estimates of flower colour variation. First, we used a subset of 200 species that we have digital photos taken with the same camera and similar light conditions to prevent artificial colour modifications. The colour of petals was assigned to the closest matching Munsell colour chip; the same person performed these measures in order to avoid erroneous assignation due to inter-observer differences in colours perception. A total of 24 colour types were identified covering shades of blue $(2.5 \mathrm{P} 7 / 6$, 10PB7/6), lilac-purple (7.5P8/4, 7.5P6/8, 7.5P6/10, 7.5P4/10, 5P6/8, 5P8/4, 5P5/10), pink (7.5RP8/4, 5RP6/10, 2.5RP5/10), yellow (5Y9/6; 5Y9/4, 5Y8.5/12), orange (5Y8/8, 2.5Y8/12, 2.5YR6/14), brown-bronze (10YR6/10, 5YR6/12, 10R5/8), green (2.5G5/5, 10GY6/8) and white (N9). We used spectral characteristics of Munsell colours to transform the categorical colour data to semi-quantitative measures of colour. Hue is one of the best colour descriptors for plant colourimetry; thus, we calculated hue values as the wavelength at peak reflectance. In order to accommodate the Brassicaceae petal colour information provided in the Floras to our 24 Munsell colour types, we generated ten colour categories. The hue of each new colour category was calculated as the mean of the hue values containing each category (i.e., among colour shades). In species with petal colour variation, including petal colour polymorphism, we scored the more common petal colour; if this information is not available, we assigned the colour derived of the presence of floral pigments (anthocyanins, carotenoids or both). The values of the ten hue categories are: $454.31 \mathrm{~nm}$ (blue), $503.55 \mathrm{~nm}$ (pink), $558.08 \mathrm{~nm}$ (lilac-purple), $572.46 \mathrm{~nm}$ (yellow), $575.43 \mathrm{~nm}$ (pale yellow), $579.38 \mathrm{~nm}$ (yellow-orange), $592.74 \mathrm{~nm}$ (orange), $589.44 \mathrm{~nm}$ (brown-bronze), $546.10 \mathrm{~nm}$ (green) and $611.37 \mathrm{~nm}$ (white).

(29) Petal colour as b CIELAB. We also used a second parameter related to petal colour,

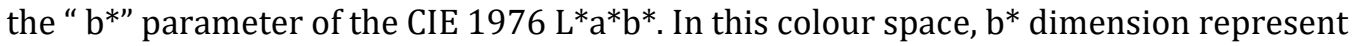
values from -100 (blue colours) to 100 (yellow colours). This metrics is recommendable for the analysis of flower colour, particularly in groups of plant species containing petals with shades of yellow, as occurs in the Brassicaceae. $b^{*}$ values were obtained with the same methodology explained in the previous trait (28). The values of the ten $b^{*}$ categories are: -18.46 (blue), -4.77 (pink), -19.71 (lilac-purple), 45.03 (pale yellow), 80.1 (yellow), 80.45 (yellow-orange), 65.3 (orange), 52.02 (brown-bronze), 29.79 (green) and 0.00 (white).

(30) Sepal hue. Sepals of Brassicaceae species are sometimes coloured, differing from the common green. As already mentioned above for traits 9 , sepals play an important role in the pollination of many plant species. We used the same method and hue values detailed in the trait 28 to score the sepal colour as hue category.

(31) Sepal colour as b CIELAB. For the same reasons mentioned above, we decided to include this trait because of the effect it can have on attracting pollinators. We used the same method and values detailed in the trait 29 to score the sepal colour as "b*" parameter of the CIE 1976 L*a*b* $^{*}$. 
bioRxiv preprint doi: https://doi.org/10.1101/2021.05.25.445642; this version posted May 26, 2021. The copyright holder for this preprint (which was not certified by peer review) is the author/funder, who has granted bioRxiv a license to display the preprint in perpetuity. It is made available under aCC-BY 4.0 International license.

Table S9. List of the phylogenies retrieved from the online repositories and from the literature to built up the Brassicaceae supertree. Within brackets appears the number of species included in the analysis of disparity

\begin{tabular}{|c|c|c|c|c|c|}
\hline Code & Species & Dated & Rooted & Focal taxa & Reference \\
\hline \multicolumn{6}{|c|}{ Phylogenies including Moricandia } \\
\hline 1 & $15[8]$ & YES & YES & Moricandia & $\begin{array}{l}\text { Perfectti, F., Gómez, J. M., González-Megías, A., Abdelaziz, M., \& Lorite, J. (2017). } \\
\text { Molecular phylogeny and evolutionary history of Moricandia DC (Brassicaceae). PeerJ, 5, } \\
\text { e3964. }\end{array}$ \\
\hline 2 & $273[255]$ & YES & YES & & $\begin{array}{l}\text { Smith, S. A., \& Brown, J. W. (2018). Constructing a broadly inclusive seed plant phylogeny. } \\
\text { American journal of botany, 105(3), 302-314 }\end{array}$ \\
\hline 3 & $1508[248]$ & YES & YES & & $\begin{array}{l}\text { Gaynor, M. L., Ng, J., \& Laport, R. G. (2018). Phylogenetic structure of plant communities: } \\
\text { are polyploids distantly related to co-occurring diploids?. Frontiers in Ecology and } \\
\text { Evolution, } 6,52 \text {. }\end{array}$ \\
\hline 4 & $195[163]$ & YES & YES & Brassiceae & $\begin{array}{l}\text { Huang, X.C., German, D.A. and Koch, M.A., 2020. Temporal patterns of diversification in } \\
\text { Brassicaceae demonstrate decoupling of rate shifts and mesopolyploidization } \\
\text { events. Annals of Botany, 125(1), pp.29-47. }\end{array}$ \\
\hline \multicolumn{6}{|c|}{ Time-calibrated phylogenies with more than 45 spp } \\
\hline 5 & $84[48]$ & YES & YES & Euclideae & $\begin{array}{l}\text { Chen, H., German, D. A., Al-Shehbaz, I. A., Yue, J., \& Sun, H. (2020). Phylogeny of } \\
\text { Euclidieae (Brassicaceae) based on plastome and nuclear ribosomal DNA data. Molecular } \\
\text { Phylogenetics and Evolution, 153, } 106940\end{array}$ \\
\hline 6 & $130[124]$ & YES & YES & & $\begin{array}{l}\text { Durka, W., \& Michalski, S. G. (2012). Daphne: a dated phylogeny of a large European flora } \\
\text { for phylogenetically informed ecological analyses: Ecological Archives E093-214. Ecology, } \\
93(10), 2297-2297\end{array}$ \\
\hline 7 & 316 [208] & YES & YES & & $\begin{array}{l}\text { Walden, N., German, D. A., Wolf, E. M., Kiefer, M., Rigault, P., Huang, X. C., Kiefer, C., } \\
\text { Schmickl R., Franzke A., Neuffer B., Mummenhoff, K., \& Koch, M.A. (2020). Nested whole- } \\
\text { genome duplications coincide with diversification and high morphological disparity in } \\
\text { Brassicaceae. Nature communications, } 11(1), 1-12\end{array}$ \\
\hline 8 & 165 [109] & YES & YES & Alysseae & $\begin{array}{l}\text { Huang, X.C., German, D.A. and Koch, M.A., 2020. Temporal patterns of diversification in } \\
\text { Brassicaceae demonstrate decoupling of rate shifts and mesopolyploidization } \\
\text { events. Annals of Botany, 125(1), pp.29-47. }\end{array}$ \\
\hline 9 & $46[26]$ & YES & YES & Anchonieae & $\begin{array}{l}\text { Huang, X.C., German, D.A. and Koch, M.A., 2020. Temporal patterns of diversification in } \\
\text { Brassicaceae demonstrate decoupling of rate shifts and mesopolyploidization } \\
\text { events. Annals of Botany, 125(1), pp.29-47. }\end{array}$ \\
\hline 10 & 265 [265] & YES & YES & Arabidae & $\begin{array}{l}\text { Huang, X.C., German, D.A. and Koch, M.A., 2020. Temporal patterns of diversification in } \\
\text { Brassicaceae demonstrate decoupling of rate shifts and mesopolyploidization } \\
\text { events. Annals of Botany, 125(1), pp.29-47. }\end{array}$ \\
\hline 11 & $84[77]$ & YES & YES & Boechereae & $\begin{array}{l}\text { Huang, X.C., German, D.A. and Koch, M.A., 2020. Temporal patterns of diversification in } \\
\text { Brassicaceae demonstrate decoupling of rate shifts and mesopolyploidization } \\
\text { events. Annals of Botany, 125(1), pp.29-47. }\end{array}$ \\
\hline 12 & $160[126]$ & YES & YES & Cardamineae & $\begin{array}{l}\text { Huang, X.C., German, D.A. and Koch, M.A., 2020. Temporal patterns of diversification in } \\
\text { Brassicaceae demonstrate decoupling of rate shifts and mesopolyploidization } \\
\text { events. Annals of Botany, 125(1), pp.29-47. }\end{array}$ \\
\hline 13 & $57[23]$ & YES & YES & Chorisporeae & $\begin{array}{l}\text { Huang, X.C., German, D.A. and Koch, M.A., 2020. Temporal patterns of diversification in } \\
\text { Brassicaceae demonstrate decoupling of rate shifts and mesopolyploidization } \\
\text { events. Annals of Botany, 125(1), pp.29-47. }\end{array}$ \\
\hline 14 & $51[28]$ & YES & YES & Coluteocarpaeae & $\begin{array}{l}\text { Huang, X.C., German, D.A. and Koch, M.A., 2020. Temporal patterns of diversification in } \\
\text { Brassicaceae demonstrate decoupling of rate shifts and mesopolyploidization } \\
\text { events. Annals of Botany, 125(1), pp.29-47. }\end{array}$ \\
\hline 15 & 110 [89] & YES & YES & Erysimeae & $\begin{array}{l}\text { Huang, X.C., German, D.A. and Koch, M.A., 2020. Temporal patterns of diversification in } \\
\text { Brassicaceae demonstrate decoupling of rate shifts and mesopolyploidization } \\
\text { events. Annals of Botany, 125(1), pp.29-47. }\end{array}$ \\
\hline 16 & 75 [55] & YES & YES & Euclidieae & $\begin{array}{l}\text { Huang, X.C., German, D.A. and Koch, M.A., 2020. Temporal patterns of diversification in } \\
\text { Brassicaceae demonstrate decoupling of rate shifts and mesopolyploidization } \\
\text { events. Annals of Botany, 125(1), pp.29-47. }\end{array}$ \\
\hline 17 & $56[53]$ & YES & YES & Heliophileae & $\begin{array}{l}\text { Huang, X.C., German, D.A. and Koch, M.A., 2020. Temporal patterns of diversification in } \\
\text { Brassicaceae demonstrate decoupling of rate shifts and mesopolyploidization } \\
\text { events. Annals of Botany, 125(1), pp.29-47. }\end{array}$ \\
\hline 18 & 139 [94] & YES & YES & Lepidieae & $\begin{array}{l}\text { Huang, X.C., German, D.A. and Koch, M.A., 2020. Temporal patterns of diversification in } \\
\text { Brassicaceae demonstrate decoupling of rate shifts and mesopolyploidization } \\
\text { events. Annals of Botany, 125(1), pp.29-47. }\end{array}$ \\
\hline 19 & 130 [117] & YES & YES & Thelypodieae & $\begin{array}{l}\text { Huang, X.C., German, D.A. and Koch, M.A., 2020. Temporal patterns of diversification in } \\
\text { Brassicaceae demonstrate decoupling of rate shifts and mesopolyploidization } \\
\text { events. Annals of Botany, 125(1), pp.29-47. }\end{array}$ \\
\hline \multicolumn{6}{|c|}{ Time-calibrated phylogenies with less than 45 spp } \\
\hline 20 & 10 & YES & YES & Aethionemeae & $\begin{array}{l}\text { Huang, X.C., German, D.A. and Koch, M.A., 2020. Temporal patterns of diversification in } \\
\text { Brassicaceae demonstrate decoupling of rate shifts and mesopolyploidization }\end{array}$ \\
\hline
\end{tabular}


bioRxiv preprint doi: https://doi.org/10.1101/2021.05.25.445642; this version posted May 26, 2021. The copyright holder for this preprint (which was not certified by peer review) is the author/funder, who has granted bioRxiv a license to display the preprint in perpetuity. It is made available under aCC-BY 4.0 International license.

30 YES YES

10 YES YES

5 YES

19 YES

6 YES

8 YES

27 YES

16 YES YES

8 YES YES

29 YES

13 YES

41 YES

17 YES

24 YES

YES

25 YES YES

23 YES

YES

$11 \mathrm{Y}$

13 YES

6 YES

34 YES

5 YES

5 YES

8 YES
Halimolobeae

Alyssopsideae

Anastaticeae

Aphragmeae

Asteae

Biscutelleae

Buniadeae

Calepineae

Camelineae

Cochlearieae

Conringieae

Cremolobeae

Crucihimalayeae

Descurainieae

Dontostemoneae

Eudemeae

Eutremeae

Hesperideae

Hillielleae

Iberideae

Isatideae

Kernereae

Malcolmieae

events. Annals of Botany, 125(1), pp.29-47.

Huang, X.C., German, D.A. and Koch, M.A., 2020. Temporal patterns of diversification in Brassicaceae demonstrate decoupling of rate shifts and mesopolyploidization events. Annals of Botany, 125(1), pp.29-47.

Huang, X.C., German, D.A. and Koch, M.A., 2020. Temporal patterns of diversification in Brassicaceae demonstrate decoupling of rate shifts and mesopolyploidization events. Annals of Botany, 125(1), pp.29-47.

Huang, X.C., German, D.A. and Koch, M.A., 2020. Temporal patterns of diversification in Brassicaceae demonstrate decoupling of rate shifts and mesopolyploidization events. Annals of Botany, 125(1), pp.29-47.

Huang, X.C., German, D.A. and Koch, M.A., 2020. Temporal patterns of diversification in Brassicaceae demonstrate decoupling of rate shifts and mesopolyploidization events. Annals of Botany, 125(1), pp.29-47.

Huang, X.C., German, D.A. and Koch, M.A., 2020. Temporal patterns of diversification in Brassicaceae demonstrate decoupling of rate shifts and mesopolyploidization events. Annals of Botany, 125(1), pp.29-47.

Huang, X.C., German, D.A. and Koch, M.A., 2020. Temporal patterns of diversification in Brassicaceae demonstrate decoupling of rate shifts and mesopolyploidization events. Annals of Botany, 125(1), pp.29-47.

Huang, X.C., German, D.A. and Koch, M.A., 2020. Temporal patterns of diversification in Brassicaceae demonstrate decoupling of rate shifts and mesopolyploidization events. Annals of Botany, 125(1), pp.29-47.

Huang, X.C., German, D.A. and Koch, M.A., 2020. Temporal patterns of diversification in Brassicaceae demonstrate decoupling of rate shifts and mesopolyploidization events. Annals of Botany, 125(1), pp.29-47.

Huang, X.C., German, D.A. and Koch, M.A., 2020. Temporal patterns of diversification in Brassicaceae demonstrate decoupling of rate shifts and mesopolyploidization events. Annals of Botany, 125(1), pp.29-47.

Huang, X.C., German, D.A. and Koch, M.A., 2020. Temporal patterns of diversification in Brassicaceae demonstrate decoupling of rate shifts and mesopolyploidization events. Annals of Botany, 125(1), pp.29-47.

Huang, X.C., German, D.A. and Koch, M.A., 2020. Temporal patterns of diversification in Brassicaceae demonstrate decoupling of rate shifts and mesopolyploidization events. Annals of Botany, 125(1), pp.29-47.

Huang, X.C., German, D.A. and Koch, M.A., 2020. Temporal patterns of diversification in Brassicaceae demonstrate decoupling of rate shifts and mesopolyploidization events. Annals of Botany, 125(1), pp.29-47.

Huang, X.C., German, D.A. and Koch, M.A., 2020. Temporal patterns of diversification in Brassicaceae demonstrate decoupling of rate shifts and mesopolyploidization events. Annals of Botany, 125(1), pp.29-47.

Huang, X.C., German, D.A. and Koch, M.A., 2020. Temporal patterns of diversification in Brassicaceae demonstrate decoupling of rate shifts and mesopolyploidization events. Annals of Botany, 125(1), pp.29-47.

Huang, X.C., German, D.A. and Koch, M.A., 2020. Temporal patterns of diversification in Brassicaceae demonstrate decoupling of rate shifts and mesopolyploidization events. Annals of Botany, 125(1), pp.29-47.

Huang, X.C., German, D.A. and Koch, M.A., 2020. Temporal patterns of diversification in Brassicaceae demonstrate decoupling of rate shifts and mesopolyploidization events. Annals of Botany, 125(1), pp.29-47.

Huang, X.C., German, D.A. and Koch, M.A., 2020. Temporal patterns of diversification in Brassicaceae demonstrate decoupling of rate shifts and mesopolyploidization events. Annals of Botany, 125(1), pp.29-47.

Huang, X.C., German, D.A. and Koch, M.A., 2020. Temporal patterns of diversification in Brassicaceae demonstrate decoupling of rate shifts and mesopolyploidization events. Annals of Botany, 125(1), pp.29-47.

Huang, X.C., German, D.A. and Koch, M.A., 2020. Temporal patterns of diversification in Brassicaceae demonstrate decoupling of rate shifts and mesopolyploidization events. Annals of Botany, 125(1), pp.29-47.

Huang, X.C., German, D.A. and Koch, M.A., 2020. Temporal patterns of diversification in Brassicaceae demonstrate decoupling of rate shifts and mesopolyploidization events. Annals of Botany, 125(1), pp.29-47.

Huang, X.C., German, D.A. and Koch, M.A., 2020. Temporal patterns of diversification in Brassicaceae demonstrate decoupling of rate shifts and mesopolyploidization events. Annals of Botany, 125(1), pp.29-47.

Huang, X.C., German, D.A. and Koch, M.A., 2020. Temporal patterns of diversification in Brassicaceae demonstrate decoupling of rate shifts and mesopolyploidization events. Annals of Botany, 125(1), pp.29-47.

Huang, X.C., German, D.A. and Koch, M.A., 2020. Temporal patterns of diversification in Brassicaceae demonstrate decoupling of rate shifts and mesopolyploidization events. Annals of Botany, 125(1), pp.29-47.

Huang, X.C., German, D.A. and Koch, M.A., 2020. Temporal patterns of diversification in 
bioRxiv preprint doi: https://doi.org/10.1101/2021.05.25.445642; this version posted May 26, 2021. The copyright holder for this preprint (which was not certified by peer review) is the author/funder, who has granted bioRxiv a license to display the preprint in perpetuity. It is made available under aCC-BY 4.0 International license.

\begin{tabular}{|c|c|c|c|c|}
\hline 45 & 26 & YES & YES & Microlepidieae \\
\hline 46 & 4 & YES & YES & Notothlaspidea \\
\hline 47 & 5 & YES & YES & Oreophytoneae \\
\hline 48 & 40 & YES & YES & Physarieae \\
\hline 49 & 20 & YES & YES & Schizopetaleae \\
\hline 50 & 23 & YES & YES & Sisymbrieae \\
\hline 51 & 23 & YES & YES & Smelowskieae \\
\hline 52 & 19 & YES & YES & Thlaspideae \\
\hline 53 & 5 & YES & YES & Turritideae \\
\hline 54 & 8 & YES & YES & Yinshanieae \\
\hline \multicolumn{5}{|c|}{ Non-time calibrated phylogenies } \\
\hline 55 & 115 & NO & YES & \\
\hline 56 & 44 & NO & NO & Erysimum \\
\hline 57 & 569 & NO & YES & \\
\hline 58 & 115 & NO & NO & \\
\hline 59 & 53 & NO & YES & \\
\hline 60 & 60 & NO & YES & Thysanocarpus \\
\hline 61 & 56 & NO & YES & \\
\hline 62 & 186 & NO & YES & \\
\hline 63 & 101 & NO & YES & \\
\hline 64 & 27 & NO & NO & Microthlaspi \\
\hline 65 & 22 & NO & YES & Alysseae \\
\hline 66 & 53 & NO & YES & \\
\hline 67 & 38 & NO & YES & Descurainia \\
\hline
\end{tabular}

Brassicaceae demonstrate decoupling of rate shifts and mesopolyploidization events. Annals of Botany, 125(1), pp.29-47.

Huang, X.C., German, D.A. and Koch, M.A., 2020. Temporal patterns of diversification in Brassicaceae demonstrate decoupling of rate shifts and mesopolyploidization events. Annals of Botany, 125(1), pp.29-47.

Huang, X.C., German, D.A. and Koch, M.A., 2020. Temporal patterns of diversification in Brassicaceae demonstrate decoupling of rate shifts and mesopolyploidization events. Annals of Botany, 125(1), pp.29-47.

Huang, X.C., German, D.A. and Koch, M.A., 2020. Temporal patterns of diversification in Brassicaceae demonstrate decoupling of rate shifts and mesopolyploidization events. Annals of Botany, 125(1), pp.29-47.

Huang, X.C., German, D.A. and Koch, M.A., 2020. Temporal patterns of diversification in Brassicaceae demonstrate decoupling of rate shifts and mesopolyploidization events. Annals of Botany, 125(1), pp.29-47.

Huang, X.C., German, D.A. and Koch, M.A., 2020. Temporal patterns of diversification in Brassicaceae demonstrate decoupling of rate shifts and mesopolyploidization events. Annals of Botany, 125(1), pp.29-47.

Huang, X.C., German, D.A. and Koch, M.A., 2020. Temporal patterns of diversification in Brassicaceae demonstrate decoupling of rate shifts and mesopolyploidization events. Annals of Botany, 125(1), pp.29-47.

Huang, X.C., German, D.A. and Koch, M.A., 2020. Temporal patterns of diversification in Brassicaceae demonstrate decoupling of rate shifts and mesopolyploidization events. Annals of Botany, 125(1), pp.29-47.

Huang, X.C., German, D.A. and Koch, M.A., 2020. Temporal patterns of diversification in Brassicaceae demonstrate decoupling of rate shifts and mesopolyploidization events. Annals of Botany, 125(1), pp.29-47.

Huang, X.C., German, D.A. and Koch, M.A., 2020. Temporal patterns of diversification in Brassicaceae demonstrate decoupling of rate shifts and mesopolyploidization events. Annals of Botany, 125(1), pp.29-47.

Huang, X.C., German, D.A. and Koch, M.A., 2020. Temporal patterns of diversification in Brassicaceae demonstrate decoupling of rate shifts and mesopolyploidization events. Annals of Botany, 125(1), pp.29-47.

Gómez, J. M., Torices, R., Lorite, J., Klingenberg, C. P., \& Perfectti, F. (2016). The role of pollinators in the evolution of corolla shape variation, disparity and integration in a highly diversified plant family with a conserved floral bauplan. Annals of Botany, 117(5), 889904.

Gómez, J. M., Perfectti, F., Abdelaziz, M., Lorite, J., Muñoz-Pajares, A. J., \& Valverde, J. (2015). Evolution of pollination niches in a generalist plant clade. New Phytologist, 205(1), 440-453.

Couvreur, T. L., Franzke, A., Al-Shehbaz, I. A., Bakker, F. T., Koch, M. A., \& Mummenhoff, K. (2010). Molecular phylogenetics, temporal diversification, and principles of evolution in the mustard family (Brassicaceae). Molecular Biology and Evolution, 27(1), 55-71.

Salariato, D. L., Manchego, M. A. C., Cano, A., \& Al-Shehbaz, I. A. (2019). Phylogenetic placement of the Peruvian-endemic genus Machaerophorus (Brassicaceae) based on molecular data and implication for its systematics. Plant Systematics and Evolution, 305(1), 77-87.

Guo, X., Liu, J., Hao, G., Zhang, L., Mao, K., Wang, X., ... \& Koch, M. A. (2017). Plastome phylogeny and early diversification of Brassicaceae. BMC genomics, 18(1), 176.

Alexander, P. J., Windham, M. D., Govindarajulu, R., Al-Shehbaz, I. A., \& Bailey, C. D. (2010). Molecular phylogenetics and taxonomy of the genus Thysanocarpus (Brassicaceae). Systematic Botany, 35(3), 559-577.

Huang, C.H., Sun, R., Hu, Y., Zeng, L., Zhang, N., Cai, L., Zhang, Q., Koch, M.A., Al-Shehbaz, I., Edger, P.P. and Pires, J.C., 2016. Resolution of Brassicaceae phylogeny using nuclear genes uncovers nested radiations and supports convergent morphological evolution. Molecular biology and evolution, 33(2), pp.394-412.

Warwick, S. I., Mummenhoff, K., Sauder, C. A., Koch, M. A., \& Al-Shehbaz, I. A. (2010). Closing the gaps: phylogenetic relationships in the Brassicaceae based on DNA sequence data of nuclear ribosomal ITS region. Plant Systematics and Evolution, 285(3-4), 209-232. Arias, T., Beilstein, M. A., Tang, M., McKain, M. R., \& Pires, J. C. (2014). Diversification times among Brassica (Brassicaceae) crops suggest hybrid formation after 20 million years of divergence. American journal of botany, 101(1), 86-91.

Ali, T., Schmuker, A., Runge, F., Solovyeva, I., Nigrelli, L., Paule, J., Buch, A.K., Xia, X., Ploch, S., Orren, O. and Kummer, V., 2016. Morphology, phylogeny, and taxonomy of Microthlaspi (Brassicaceae: Coluteocarpeae) and related genera. Taxon, 65(1), 79-98. Cecchi, L., Gabbrielli, R., Arnetoli, M., Gonnelli, C., Hasko, A., \& Selvi, F. (2010). Evolutionary lineages of nickel hyperaccumulation and systematics in European Alysseae (Brassicaceae): evidence from nrDNA sequence data. Annals of Botany, 106(5), 751-767. Soza, V. L., \& Di Stilio, V. S. (2014). Pattern and process in the evolution of the sole dioecious member of Brassicaceae. EvoDevo, 5(1), 42 .
Goodson, B. E., Rehman, S. K., \& Jansen, R. K. (2011). Molecular systematics and 
bioRxiv preprint doi: https://doi.org/10.1101/2021.05.25.445642; this version posted May 26, 2021. The copyright holder for this preprint (which was not certified by peer review) is the author/funder, who has granted bioRxiv a license to display the preprint in perpetuity. It is made available under aCC-BY 4.0 International license.

\begin{tabular}{|c|c|c|c|c|}
\hline 68 & 15 & NO & NO & Thlaspi \\
\hline 69 & 101 & NO & NO & \\
\hline 70 & 130 & NO & NO & \\
\hline 71 & 103 & NO & YES & \\
\hline 72 & 56 & NO & YES & \\
\hline 73 & 223 & NO & YES & \\
\hline 74 & 97 & NO & NO & Vella \\
\hline 75 & 109 & NO & NO & Vella \\
\hline 76 & 49 & NO & YES & Pachycladon \\
\hline 77 & 189 & NO & YES & \\
\hline 78 & 195 & NO & NO & Brassiceae \\
\hline 79 & 598 & NO & YES & \\
\hline 8 & 370 & NO & YES & \\
\hline
\end{tabular}

biogeography of Descurainia (Brassicaceae) based on nuclear ITS and non-coding chloroplast DNA. Systematic Botany, 36(4), 957-980.

Koch, M., \& Al-Shehbaz, I. A. (2004). Taxonomic and phylogenetic evaluation of the American. Systematic Botany, 29(2), 375-384.

From TreeBase - d13 [R-package APE, Fri May 31 09:08:01 2019]

Salariato, D. L., Manchego, M. A. C., Cano, A., \& Al-Shehbaz, I. A. (2019). Phylogenetic placement of the Peruvian-endemic genus Machaerophorus (Brassicaceae) based on molecular data and implication for its systematics. Plant Systematics and Evolution, 305(1), 77-87.

From TreeBase - T3061 [R-package APE, Thu Oct 15 18:34:08 2020]

From TreeBase - Parrya [R-package APE, Thu Oct 15 19:34:09 2020] - Nikolov, L.A., Shushkov, P., Nevado, B., Gan, X., Al-Shehbaz, I.A., Filatov, D., Bailey, C.D. and Tsiantis, M., 2019. Resolving the backbone of the Brassicaceae phylogeny for investigating trait diversity. New Phytologist, 222(3), pp.1638-1651.

From TreeBase - varios [R-package APE, Fri Oct 16 07:38:56 2020]

Simon-Porcar, V. I., Perez-Collazos, E., \& Catalan, P. (2015). Phylogeny and systematics of the western Mediterranean Vella pseudocytisus-V. aspera complex (Brassicaceae). Turkish Journal of Botany, 39(3), 472-486.

Crespo, M.B., Lledó, M.D., Fay, M.F. and Chase, M.W., 2000. Subtribe Vellinae (Brassiceae, Brassicaceae): a combined analysis of ITS nrDNA sequences and morphological data. Annals of Botany, 86(1), pp.53-62.

Joly, S., Heenan, P.B. and Lockhart, P.J., 2009. A Pleistocene inter-tribal

allopolyploidization event precedes the species radiation of Pachycladon (Brassicaceae) in New Zealand. Molecular phylogenetics and evolution, 51(2), pp.365-372.

German, D.A., Friesen, N., Neuffer, B., Al-Shehbaz, I.A. and Hurka, H., 2009. Contribution to ITS phylogeny of the Brassicaceae, with special reference to some Asian taxa. Plant Systematics and Evolution, 283(1-2), pp.33-56.

BrassiBase ITS tree- https://brassibase.cos.uni-

heidelberg.de/?action=phlv\&subaction=Brassiceae

Bailey, C.D., Koch, M.A., Mayer, M., Mummenhoff, K., O'Kane Jr, S.L., Warwick, S.I., Windham, M.D. and Al-Shehbaz, I.A., 2006. Toward a global phylogeny of the Brassicaceae. Molecular biology and evolution, 23(11), pp.2142-2160.

Friesen, N., Čalasan, A.Ž., Neuffer, B., German, D.A., Markov, M. and Hurka, H., 2020.

Evolutionary history of the Eurasian steppe plant Schivereckia podolica (Brassicaceae) and its close relatives. Flora, p.151602. 
Table S10. List of ecologists kindly sharing unpublished information on Brassicaceae pollinators. The host institutions are those at the time of the contact with our team.

\begin{tabular}{|c|c|c|}
\hline Last Name & First Name & Host institution \\
\hline Abdelaziz & Mohamed & University of Granada (Spain) \\
\hline Aizen & Marcelo & Universidad Nacional del Comahue-CONICET (Argentina) \\
\hline Aguado & Luis Oscar & Castilla y Leon Regional Goverment (Spain) \\
\hline Alarcon & Ruben & University Arizona (USA) \\
\hline Amat & Elena & Real Jardín Botánico de Madrid (Spain) \\
\hline Arista & Montserrat & University of Seville (Spain) \\
\hline Banza & Paula & University of Hull (UK) \\
\hline Barbir & Jelena & ICA-CSIC (Spain) \\
\hline Bartomeus & Ignasi & EBD-CSIC (Spain) \\
\hline Bergerot & Benjamin & University of Rennes (France) \\
\hline Bommarco & Riccardo & Swedish University of Agricultural Sciences (Sweden) \\
\hline Bosch & Jordi & CREAF-UAB (Spain) \\
\hline Bruinsma & Maaike & Leiden University (The Netherlands) \\
\hline Burkle & Laura & Montana State University (USA) \\
\hline CaraDonna & Paul & Northwestern University (USA) \\
\hline Cartar & Ralph & University of Calgary (Canada) \\
\hline Castro & Silvia & University of Coimbra (Portugal) \\
\hline Castro-Urgal & Rocio & IMEDEA-CSIC (Spain) \\
\hline Chacoff & Natacha & Universidad Nacional del Comahue-CONICET (Argentina) \\
\hline Conner & Jeffrey & Michigan State University (USA) \\
\hline Cuerda & David & Junta de Andalucía (Spain) \\
\hline Dennis & Roger L. H. & Staffordshire University (UK) \\
\hline Ebeling & Anne & University of Jena (Germany) \\
\hline Escudero & Adrián & Universidad Rey Juan Carlos (Spain) \\
\hline Evans & Darren & University of Hull (UK) \\
\hline Fernández & Juande & Greenpeace (Spain) \\
\hline Ferrero & Victoria & University of León (Spain) \\
\hline Fründ & Jochen & Georg-August-Universität (Germany) \\
\hline Fultz & Jessica & Idaho State University (USA) \\
\hline Garbuzov & Mihail & University Sussex (UK) \\
\hline García & Begoña & IPE-CSIC (Spain) \\
\hline García-Camacho & Raúl & Universidad Rey Juan Carlos (Spain) \\
\hline García & Yedra & CIDE (University of New Brunswick) \\
\hline García de Lucas & Sandra & Junta de Andalucía (Spain) \\
\hline Giménez & Luis & Universidad Rey Juan Carlos (Spain) \\
\hline Iriondo & José María & Universidad Rey Juan Carlos (Spain) \\
\hline Junker & Robert R. & University of Salzburg (Austria) \\
\hline Kuppler & Jonas & ULM University (Germany) \\
\hline Lance & Richard & Northern Arizona University (USA) \\
\hline Lara & Carlos & Universidad Rey Juan Carlos (Spain) \\
\hline Lázaro & Amparo & IMEDEA-CSIC (Spain) \\
\hline Lorite & Juan & University of Granada (Spain) \\
\hline Louadi & Kamel & University Frères Mentouri Konstantine (Algeria) \\
\hline Loureiro & João & University of Coimbra (Portugal) \\
\hline Lucas-Barbosa & Dani & Wageningen University (The Netherlands) \\
\hline Majetic & Cassey J. & Saint Mary's College Indiana (USA) \\
\hline Marcos & Maria Ángeles & Universidad de Alicante (Spain) \\
\hline Medel & Rodrigo & University of Santiago de Chile (Chile) \\
\hline Meindl & George & Binghamton University (USA) \\
\hline Melen & Miranda & University of California-Santa Cruz (USA) \\
\hline Méndez & Marcos & Universidad Rey Juan Carlos (Spain) \\
\hline Menéndez & Rosa & University of Lancaster (UK) \\
\hline
\end{tabular}


bioRxiv preprint doi: https://doi.org/10.1101/2021.05.25.445642; this version posted May 26, 2021. The copyright holder for this preprint (which

was not certified by peer review) is the author/funder, who has granted bioRxiv a license to display the preprint in perpetuity. It is made available under aCC-BY 4.0 International license.

\begin{tabular}{|c|c|c|}
\hline Milla & Rubén & Universidad Rey Juan Carlos (Spain) \\
\hline Morales & Carolina & Universidad Nacional del Comahue-CONICET (Argentina) \\
\hline Morente & Javier & Universidad Rey Juan Carlos (Spain) \\
\hline Muñoz-Pajares & A. Jesus & University of Coimbra (Portugal) \\
\hline Norfolk & Olivia & University of Nottingham (UK) \\
\hline Norton & Nicholas & Washington State University (USA) \\
\hline O’Malley & Rachel & San Jose State University (USA) \\
\hline Ojeda & Fernando & University of Cádiz (Spain) \\
\hline Pelayo & Roxibel & Universidad de las Andes (Venezuela) \\
\hline Petanidou & Theodora & University of the Aegean (Greece) \\
\hline Razanajatovo & Mialy & University Konstanz (Germany) \\
\hline Roberts & S.P.M. & University of Reading (UK) \\
\hline Santamaría & Silvia & Universidad Rey Juan Carlos (Spain) \\
\hline Schlinkert & Hella & University Goettingen (Germany) \\
\hline Schrader & Julian & University Goettingen (Germany) \\
\hline Schupp & Eugene $\mathrm{W}$. & Utah State University (USA) \\
\hline Simaika & John P. & Stellenbosch University (South Africa) \\
\hline Simanonok & Michael P. & MSU- Northern Prairie Wildlife Research Center (USA) \\
\hline Stang & Martina & University of Leiden (The Netherlands) \\
\hline Stanley & Dara A. & Trinity College Dublin (Ireland) \\
\hline Stout & Jane & Trinity College Dublin (Ireland) \\
\hline Strauss & Sharon & University of California at Davis (USA) \\
\hline Torices & Rubén & University Lausanne (Switzerland) \\
\hline Traveset & Anna & IMEDEA-CSIC (Spain) \\
\hline Tscharntke & Teja & University of Göttingen (Germany) \\
\hline Tur & Cristina & IMEDEA-CSIC (Spain) \\
\hline Valido & Alfredo & IPNA-CSIC (Spain) \\
\hline Valverde & Javier & EBD-CSIC (Spain) \\
\hline Vargas & Pablo & Real Jardín Botánico de Madrid (Spain) \\
\hline Warzecha & Daniela & Goethe University (Germany) \\
\hline Whittall & Justen & Santa Clara University (USA) \\
\hline Winfree & Rachael & Rutgers University (USA) \\
\hline Wonneck & Mark & University of Calgary (Canada) \\
\hline Zink & Lindsay & University of Calgary (Canada) \\
\hline
\end{tabular}


Table S11. Brief description of the functional groups of the insects visiting the flowers of the studied species.

\begin{tabular}{|c|c|c|c|c|c|c|c|}
\hline & Functional Group & Body length & Resource & Behavioural notes & Type of visits & Order & Examples \\
\hline 1 & $\begin{array}{l}\text { Long-tongued extra- } \\
\quad \text { large bees }\end{array}$ & $\geq 15 \mathrm{~mm}$ & Nectar + Pollen & Partially introducing the head in the flower & Legitimate & Hymenoptera & Anthophoridae, Apidae \\
\hline 2 & $\begin{array}{l}\text { Long-tongued large } \\
\text { bees }\end{array}$ & $10-15 \mathrm{~mm}$ & Nectar + Pollen & Partially introducing the head in the flower & Legitimate & Hymenoptera & Anthophoridae \\
\hline 3 & $\begin{array}{c}\text { Long-tongued medium- } \\
\text { sized bees }\end{array}$ & $<10 \mathrm{~mm}$ & Nectar + Pollen & Partially introducing the head in the flower & Legitimate & Hymenoptera & Anthophoridae \\
\hline 4 & Honeybees & $6-12 \mathrm{~mm}$ & Nectar + Pollen & Introducing the whole head in the flower & Legitimate & Hymenoptera & Apidae (Apis spp.) \\
\hline 5 & $\begin{array}{l}\text { Short-tongued extra- } \\
\quad \text { large bees }\end{array}$ & $\geq 15 \mathrm{~mm}$ & Nectar + Pollen & Introducing the head in the flower & Legitimate & Hymenoptera & Apidae \\
\hline 6 & $\begin{array}{l}\text { Short-tongued large } \\
\text { bees }\end{array}$ & $>10 \mathrm{~mm}$ & Pollen + Nectar & Introducing the whole head in the flower & Legitimate & Hymenoptera & Halictidae, Megachilidae, Colletidae Andrenidae \\
\hline 7 & $\begin{array}{l}\text { Short-tongued } \\
\text { medium-sized bees }\end{array}$ & $5-10 \mathrm{~mm}$ & Pollen + Nectar & Introducing the whole head in the flower & Legitimate & Hymenoptera & $\begin{array}{l}\text { Halictidae, Colletidae, Andrenidae, Apidae } \\
\text { Xylocopinae, Apidae Nomidinae }\end{array}$ \\
\hline 8 & $\begin{array}{l}\text { Short-tongued small } \\
\text { bees }\end{array}$ & $2-5 \mathrm{~mm}$ & Pollen + Nectar & $\begin{array}{l}\text { They access the nectar legitimately or from between } \\
\text { the sepals }\end{array}$ & $\begin{array}{c}\text { Illegitimate }+ \\
\text { Legitimate }\end{array}$ & Hymenoptera & $\begin{array}{l}\text { Halictidae, Colletidae, Andrenidae, Apidae } \\
\text { Xylocopinae, Apidae Nomidinae }\end{array}$ \\
\hline 9 & $\begin{array}{l}\text { Short-tongued extra- } \\
\text { small bees }\end{array}$ & $<2 \mathrm{~mm}$ & Nectar + Pollen & $\begin{array}{l}\text { They access the nectar legitimately or from between } \\
\text { the sepals }\end{array}$ & $\begin{array}{l}\text { Legitimate }+ \\
\text { Illegitimate }\end{array}$ & Hymenoptera & Halictidae, Colletidae \\
\hline 10 & Large ants & $>2 \mathrm{~mm}$ & Nectar & $\begin{array}{l}\text { They can introduce the whole body in the flower to } \\
\text { reach the nectar }\end{array}$ & $\begin{array}{l}\text { Legitimate }+ \\
\text { Illegitimate }\end{array}$ & Hymenoptera & Formicidae \\
\hline 11 & Small ants & $<2 \mathrm{~mm}$ & Nectar & Mostly sipping nectar from between sepals & $\begin{array}{c}\text { Illegitimate }+ \\
\text { Legitimate }\end{array}$ & Hymenoptera & Formicidae \\
\hline 12 & Large pollen wasps & Variable & Pollen & Partially introducing the head in the flower & Legitimate & Hymenoptera & Massarinae \\
\hline 13 & $\begin{array}{c}\text { Large nectar-collecting } \\
\text { wasps }\end{array}$ & $>7 \mathrm{~mm}$ & Nectar & Partially introducing the head in the flower & Legitimate & Hymenoptera & Vespidae \\
\hline 14 & $\begin{array}{c}\text { Small nectar-collecting } \\
\text { wasps }\end{array}$ & $\begin{array}{l}\text { Usually } \\
<3 \mathrm{~mm}\end{array}$ & Nectar & Mostly sipping nectar from between sepals & $\begin{array}{c}\text { Illegitimate }+ \\
\text { Legitimate }\end{array}$ & Hymenoptera & Chalcidoidea, Ichneumonoidea \\
\hline 15 & Hovering long-tongued & Variable & Nectar + & Hovering while nectaring and collecting some pollen & Legitimate & Diptera & Bombyliidae (Bombylius) \\
\hline
\end{tabular}




\begin{tabular}{|c|c|c|c|c|c|c|c|}
\hline & flies & & Pollen & & & & \\
\hline 16 & $\begin{array}{l}\text { Non-hovering long } \\
\text { tongued flies }\end{array}$ & Variable & Nectar & Nectaring without hovering; long buccal apparatus & Legitimate & Diptera & Bombyliidae, Tachinidae, Nemestrinidae, \\
\hline 17 & Large hoverflies & $>5 \mathrm{~mm}$ & Pollen & Collect pollen without entering the flower & Legitimate & Diptera & Syrphidae (Eristalini) \\
\hline 18 & Small hoverflies & $<5 \mathrm{~mm}$ & $\begin{array}{l}\text { Pollen }+ \\
\text { Nectar }\end{array}$ & $\begin{array}{l}\text { Collect pollen without entering the flower and } \\
\text { sometimes sip nectar from between the sepals }\end{array}$ & $\begin{array}{l}\text { Legitimate + } \\
\text { Illegitimate }\end{array}$ & Diptera & Syrphidae \\
\hline 19 & Large flies & $>5 \mathrm{~mm}$ & $\begin{array}{l}\text { Nectar }+ \\
\text { Pollen }\end{array}$ & $\begin{array}{l}\text { Collect pollen without entering the flower and } \\
\text { nectar }\end{array}$ & $\begin{array}{l}\text { Legitimate + } \\
\text { Illegitimate }\end{array}$ & Diptera & $\begin{array}{l}\text { Muscidae, Calliphoridae, Tabanidae, } \\
\text { Scatophagidae, Anthomyiidae }\end{array}$ \\
\hline 20 & Small flies & $<5 \mathrm{~mm}$ & $\begin{array}{l}\text { Nectar }+ \\
\text { Pollen }\end{array}$ & Mostly sipping nectar & $\begin{array}{l}\text { Illegitimate + } \\
\text { Legitimate }\end{array}$ & Diptera & $\begin{array}{l}\text { Muscidae, Anthomyiidae, Micetophyliidae, } \\
\text { Drosophilidae, Stratiomyidae }\end{array}$ \\
\hline 21 & $\begin{array}{l}\text { Long tongued small } \\
\text { flies }\end{array}$ & $<5 \mathrm{~mm}$ & Nectar & Sipping nectar & $\begin{array}{l}\text { Illegitimate + } \\
\text { Legitimate }\end{array}$ & Diptera & Bibionidae, Empididae \\
\hline 22 & Large beetles & $>7 \mathrm{~mm}$ & Mostly Pollen & $\begin{array}{l}\text { Consuming not only pollen, also anthers, petals, and } \\
\text { other floral parts }\end{array}$ & $\begin{array}{l}\text { Legitimate + } \\
\text { Illegitimate }\end{array}$ & Coleoptera & Cetonidae, Lagridae, Mylabridae, Allecuninae \\
\hline 23 & Small beetles & $<7 \mathrm{~mm}$ & Pollen + Nectar & $\begin{array}{l}\text { Consuming pollen during legitimate visits and also } \\
\text { robbing nectar from the bottom part of the flowers }\end{array}$ & $\begin{array}{l}\text { Legitimate + } \\
\text { Illegitimate }\end{array}$ & Coleoptera & $\begin{array}{l}\text { Melyridae (Malachidae, Dasytidae), Cleridae, } \\
\text { Oedemeridae, Elateridae, Bruchidae, Buprestidae, } \\
\text { Chrysomelidae }\end{array}$ \\
\hline 24 & Small diving beetles & $<3 \mathrm{~mm}$ & Nectar + Pollen & $\begin{array}{l}\text { Entering completely into the flower, crawling down } \\
\text { the corolla for nectar }\end{array}$ & Legitimate & Coleoptera & Nitidulidae, Dermestidae, Phalacridae \\
\hline 25 & Large Butterflies & $\geq 20 \mathrm{~mm}$ & Nectar & $\begin{array}{l}\text { Feeding on nectar both from inside the flower and } \\
\text { between the sepals }\end{array}$ & Legitimate & Lepidoptera & Nymphalidae, ,Papilionidae, Pieridae \\
\hline 26 & Small Butterflies & $<20 \mathrm{~mm}$ & Nectar & $\begin{array}{l}\text { Feeding on nectar both from inside the flower and } \\
\text { between the sepals }\end{array}$ & Legitimate & Lepidoptera & Lycaenidae, Pieridae, Hesperidae \\
\hline 27 & Hawkmoths & $>7 \mathrm{~mm}$ & Nectar & Hovering to sip nectar & Legitimate & Lepidoptera & Sphingidae \\
\hline 28 & Large moths & $>3 \mathrm{~mm}$ & Nectar & Sipping nectar while landed onto the corolla & Legitimate & Lepidoptera & Crambidae, Noctuidae \\
\hline 29 & Small moths & $<3 \mathrm{~mm}$ & Nectar & Sipping nectar without entering the flower & $\begin{array}{l}\text { Illegitimate + } \\
\text { Legitimate }\end{array}$ & Lepidoptera & Adelidae, Plutellidae \\
\hline 30 & Nocturnal moths & variable & Nectar & $\begin{array}{l}\text { Sipping nectar while landed onto the corolla or by } \\
\text { hovering; Visiting the flowers at night }\end{array}$ & Legitimate & Lepidoptera & Noctuidae \\
\hline
\end{tabular}




\begin{tabular}{|c|c|c|c|c|c|c|c|}
\hline 31 & Bugs & variable & Nectar & $\begin{array}{l}\text { Sipping nectar without entering the flower. Also } \\
\text { acting as sapsuckers in vegetative tissues }\end{array}$ & $\begin{array}{l}\text { Legitimate }+ \\
\text { lllegitimate }\end{array}$ & Hemiptera & Lygaeidae, Pentatomidae \\
\hline 32 & Thrips & $<3 \mathrm{~mm}$ & Pollen & Feeding from inside the flowers & Legitimate & Thysanoptera & \\
\hline 33 & Grasshoppers & variable & $\begin{array}{c}\text { Pollen + Floral } \\
\text { parts }\end{array}$ & Mostly nymphs & Legitimate & Orthoptera & \\
\hline 34 & Aphids & $<2 \mathrm{~mm}$ & Nectar & Mostly winged individuals & Legitimate & Hemiptera & Aphidoidea \\
\hline 35 & Earwig & $>15 \mathrm{~mm}$ & Pollen & & $\begin{array}{l}\text { Legitimate + } \\
\text { Illegitimate }\end{array}$ & & \\
\hline 36 & Lacewing & $>15 \mathrm{~mm}$ & Pollen + Nectar & & $\begin{array}{l}\text { Legitimate }+ \\
\text { Illegitimate }\end{array}$ & Neuroptera & Chrysopidae \\
\hline 37 & Snakeflies & $>8 \mathrm{~mm}$ & Pollen + Nectar & & $\begin{array}{l}\text { Legitimate }+ \\
\text { lllegitimate }\end{array}$ & Raphidioptera & \\
\hline 38 & Birds & 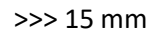 & Nectar & & Legitimate & Passeriformes & \\
\hline 39 & Springtails & $<2 \mathrm{~mm}$ & Nectar & & $\begin{array}{l}\text { Legitimate }+ \\
\text { lllegitimate }\end{array}$ & & \\
\hline 40 & Mites & $<2 \mathrm{~mm}$ & Nectar & & $\begin{array}{l}\text { Legitimate + } \\
\text { Illegitimate }\end{array}$ & & \\
\hline 41 & Spiders & $<2 \mathrm{~mm}$ & Unknown & & Illegitimate & & \\
\hline 42 & Larvae & variable & Unknown & & Illegitimate & & \\
\hline 43 & Others & variable & Unknown & & Illegitimate & & \\
\hline
\end{tabular}


bioRxiv preprint doi: https://doi.org/10.1101/2021.05.25.445642; this version posted May 26, 2021. The copyright holder for this preprint (which was not certified by peer review) is the author/funder, who has granted bioRxiv a license to display the preprint in perpetuity. It is made available under aCC-BY 4.0 International license. 